\title{
An increase in integrin-linked kinase non- canonically confers NF-kB-mediated growth advantages to gastric cancer cells by activating ERK1/2
}

Po-Chun Tseng ${ }^{1}$, Chia-Ling Chen ${ }^{2}$, Yan-Shen Shan ${ }^{1,3}$, Wen-Teng Chang ${ }^{4}$, Hsiao-Sheng Liư ${ }^{5}$, Tse-Ming Hong ${ }^{1}$, Chia-Yuan Hsieh ${ }^{1}$, Sheng-Hsiang Lin $^{1}$ and Chiou-Feng Lin ${ }^{1,6,7,8^{*}}$

\begin{abstract}
Background: Increased activity or expression of integrin-linked kinase (ILK), which regulates cell adhesion, migration, and proliferation, leads to oncogenesis. We identified the molecular basis for the regulation of ILK and its alternative role in conferring ERK1/2/NF-KB-mediated growth advantages to gastric cancer cells.

Results: Inhibiting ILK with short hairpin RNA or T315, a putative ILK inhibitor, abolished NF-KB-mediated the growth in the human gastric cancer cells AGS, SNU-1, MKN45, and GES-1. ILK stimulated Ras activity to activate the c-Raf/MEK1/2/ ERK1/2/ribosomal S6 kinase/inhibitor of KBa/NF-KB signaling by facilitating the formation of the IQ motif-containing GTPase-activating protein 1 (IQGAP1)-Ras complex. Forced enzymatic ILK expression promoted cell growth by facilitating ERK1/2/NF-KB signaling. PI3K activation or decreased PTEN expression prolonged ERK1/2 activation by protecting ILK from proteasome-mediated degradation. C-terminus of heat shock cognate 70 interacting protein, an HSP90-associated E3 ubiquitin ligase, mediated ILK ubiquitination to control PI3K- and HSP90-regulated ILK stabilization and signaling. In addition to cell growth, the identified pathway promoted cell migration and reduced the sensitivity of gastric cancer cells to the anticancer agents 5-fluorouracil and cisplatin. Additionally, exogenous administration of EGF as well as overexpression of EGFR triggered ILK- and IQGAP1-regulated ERK1/2/NF-KB activation, cell growth, and migration. Conclusion: An increase in ILK non-canonically promotes ERK1/2/NF-KB activation and leads to the growth of gastric cancer cells.
\end{abstract}

Keywords: ILK, Cell growth, IQGAP1, ERK1/2, NK-KB

\section{Background}

Integrin-linked kinase (ILK), a 59-kDa serine/threonine kinase, directly interacts with the cytoplasmic domain of $\beta 1$ integrin [1]. ILK comprises three domains: N-terminal ankyrin (ANK) repeats, a central pleckstrin homology $(\mathrm{PH})$-like domain, and a C-terminal kinase domain $[2,3]$. Integrin-mediated cell-extracellular matrix (ECM) adhesion or growth factors activate phosphatidylinositol 3-kinase (PI3K) to phosphorylate membrane-bound PI

\footnotetext{
* Correspondence: cflin2014@tmu.edu.tw

${ }^{8}$ Department of Microbiology and Immunology, College of Medicine, Taipei Medical University, Taipei 110, Taiwan

Full list of author information is available at the end of the article
}

4,5-bisphosphate (PIP2) and generate PI 3,4,5-triphosphate (PIP3), which binds to the PH-like domain of ILK and activates ILK $[4,5]$. After ILK activation, the Cterminal kinase domain of ILK can bind to various proteins, including AKT, affixin, $\beta$-parvin, glycogen synthase kinase (GSK)-3 $\beta$, calponin homology-containing ILKbinding protein, the $20-\mathrm{kDa}$ regulatory light chains of myosin (LC20), the myosin-targeting subunit of myosin light chain phosphatase (MYPT1), paxillin, $\alpha$-NAC, and the protein phosphatase inhibitors PHI-1, KEPI, and CPI-17 $[2,3,6,7]$. The $\mathrm{N}$-terminal ANK repeats mediate the interaction of ILK with ILKAP, a protein phosphatase $2 \mathrm{C}$ family member, and $\mathrm{PINCH}$, an LIM domain-only adaptor protein. ILK can be considered a PIP3-interacting protein 
downstream of PI3K; its effects are blocked by phosphatase and tensin homolog deleted on chromosome 10 (PTEN) [8,9]. PTEN suppresses tumors by dephosphorylating PIP3 [10,11].

ILK plays a vital role in regulating various cellular processes, including proliferation, survival, migration, cell cycle progression, and angiogenesis; increased activity or expression of ILK leads to oncogenesis [2,3]. Besides modulating its partner proteins for cellular processes, ILK is hypothesized to be involved in an intracellular signal transduction network. Mechanistically, ILK directly phosphorylates AKT on Ser473 and GSK-3 $\beta$ on Ser9 $[4,9]$ to mediate $\beta$-catenin translocation and regulate AP-1 expression for tumor cell proliferation [12]. NF- $\mathrm{kB}$ activation is essential for ILK-mediated oncogenic processes, such as anti-apoptotic activity [13], survival promotion [14], epithelial-mesenchymal transition [15], cellular extension and resistance to apoptosis [16], angiogenesis [17], and migration, invasion, and metastasis [18-20]. In addition, NF- $\mathrm{KB}$ activation is required for the canonical regulation of IKK $\alpha$ and IKKß by the ILK/AKT pathway. To trigger cell migration, ILK can activate the small GTPases RAC and CDC42 [21]. Furthermore, ILK regulates ERK1/2 activation in myogenic differentiation [22]. Increased expression of microRNA-143 and microRNA-145, which target ILK, inhibits AKT and ERK1/2 pathways [23]. However, the molecular mechanism underlying ILK-mediated ERK1/ 2 activation remains unknown.

The stimulation of cells by growth factors and cytokines as well as cellular interaction with ECM increase ILK activity [24]. In addition to the molecular regulation of PI3K/PTEN by ILK, Aoyagi et al. identified ILK as a new heat shock protein (HSP) 90 client protein and found that pharmacologically inhibiting HSP90 resulted in ILK degradation in a proteasome-dependent manner [25]. Furthermore, the HSP90-associated E3 ubiquitin ligase $\mathrm{C}$-terminus of heat shock cognate 70 interacting protein (CHIP) causes ILK degradation [26]. Hashiramoto et al. demonstrated that HSP90 stabilized ILK and sustained AKT and ERK1/2 activation [16]. Thus, we speculate a relationship between ILK stability and the activation of its downstream kinases. Ras/MAPK pathway signaling is essential for tumorigenesis [27]. Increased ILK expression is related to high-grade gastric cancer [28], prostate cancer [29], and non-small cell lung cancer [30], although cells in these cancers commonly harbor Ras mutations [31-33]. Targeting ILK with siRNA decreases gastric cancer cell invasion, proliferation, and growth through an unknown mechanism [34]. Regarding the possibility that ILK acts upstream of NF-kB by regulating IKK $\alpha$ [13], which has been implicated in gastric tumorigenesis [35], ILK is speculated to activate cell growth through an NF-kBregulated pathway. Using gastric cancer cells (AGS,
MKN45, and SNU-1), we studied the molecular regulation of ILK and identified a non-canonical pathway of ILK-regulated ERK1/2 activation for NF- $\mathrm{B}$-mediated gastric cancer cell growth, migration, and survival promotion.

\section{Results}

ILK activity and expression are essential for NF-KBmediated cell growth

Increased activity or expression of ILK enhances tumorigenesis by promoting cell growth [6]. RNAi-based ILK silencing attenuates gastric cancer cell growth [34], whereas ILK overexpression is related to gastric tumorigenesis [28]. In human gastric tumors and AGS-derived nodules in BALB/c mice, Ki-67-positive proliferating cells coexpressed ILK as demonstrated by the fluorescence-based immunostaining (Figure 1A) and AEC-based immunostaining (Additional file 1: Supplemental materials and methods; Additional file 2: Figure S1) experiments. To investigate the possible mechanisms underlying ILKmediated gastric cancer cell growth, several gastric epithelial cell lines were characterized according to their different cell growth rates, which were higher for the AGS and SNU-1 cells and lower for the MKN45 and GES-1 cells, and used in this study (Additional file 3: Figure S2A). Compared with the MKN45 cells, the AGS and SNU-1 cells also had elevated ILK expression (Additional file 3: Figure S2B and S2C). A lentiviral-based shRNA was used to silence ILK genetically in the AGS, SNU-1, MKN45, and GES-1 gastric epithelial cells (Figure 1B, upper panel) as well as in A549 and H1975 human lung adenocarcinoma cells, HK-2 human renal proximal tubular epithelial cells, and THP-1 human monocytic cells (Additional file 3: Figure S2D). In these cells, ILK silencing significantly $(P<0.05)$ decreased cell growth (Figure 1B; Additional file 3: Figure S2E). Furthermore, treating cells with the ILK inhibitor T315 [36] significantly $(P<0.05)$ and dosedependently retarded cell growth (Figure $1 C$ ) without cytotoxicity (data not shown). Additionally, decreased colony formation was observed in ILK-silenced AGS cells (Additional file 3: Figure S2F). Thus, gene silencing (Additional file 3: Figure S2G) and pharmacological methods (Additional file 3: Figure $\mathrm{S} 2 \mathrm{H}$ ) to suppress ILK activity or overexpression led to cell cycle arrest at the $\mathrm{G}_{1}$ phase. These results show a growth-promoting role of ILK.

To characterize the features of ILK-regulated cell growth, NF- $\mathrm{kB}$ signaling was examined because ILK can act upstream of NF-kB by regulating IKK $\alpha$ [13]. By immunostaining, the coexpression of ILK and phosphorylated NF- $\mathrm{kB}$ (Ser536) was observed in human and mouse gastric tissues (Figure 1D), and their coexpression significantly $(P<0.01)$ and positively correlated with the number of proliferating cells, which is indicated by 55 


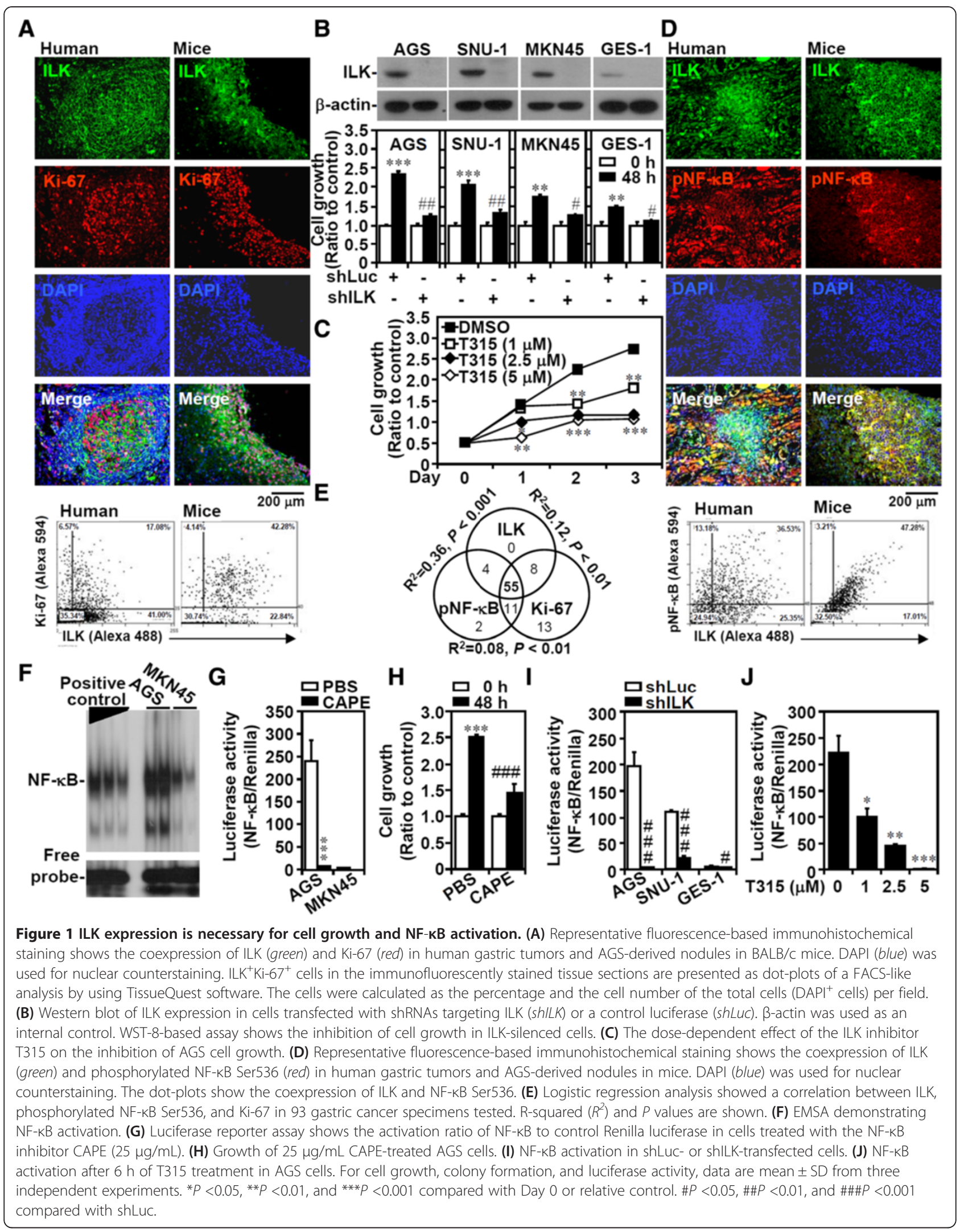


triple-positive cases of the total 93 gastric cancer specimens (Figure 1E; Additional file 4: Figure S3). Immunostaining for NF- $\mathrm{kB}$ nuclear translocation (Additional file 3: Figure S2I), EMSA (Figure 1F), and promoter assays (Figure 1G) confirmed the constitutive activation of NF- $\mathrm{kB}$ in the AGS cells but not in the MKN45 cells. Treating cells with the NF-kB inhibitor CAPE significantly $(P<0.001)$ reduced NF$\mathrm{KB}$ activation (Figure 1G) and cell growth (Figure $1 \mathrm{H}$ ). Either ILK silencing (Figure 1I; Additional file 3: Figure S2J) or T315 treatment (Figure 1J) significantly $(P<0.05)$ stopped NF- $\mathrm{kB}$ activity. These results demonstrated that ILK is indispensable for cell growth in the cell lines tested because it facilitates NF- $\mathrm{kB}$ activation in gastric cancers.

\section{ILK regulates Ras activity by facilitating the complex of IQGAP1-Ras to control MAPK-activated NF-KB}

Because AGS cells harbor PIK3CA and KRAS mutations [37], we examined possible regulatory effects of ILK on the modulation of NF- $\kappa B$ activity by these 2 kinases [38]. Using a Human Phospho-MAPK Array Kit, we identified 10 kinases that were more highly expressed in the AGS cells than in the MKN45 cells. These kinases mostly acted downstream of the PI3K and MAPK signaling pathways (Additional file 5: Figure S4A). By western blotting, we confirmed an increased phosphorylation of AKT, ERK1/2, and IкB $\alpha$ accompanied by IкB $\alpha$ degradation in the AGS cells (Figure 2A). The pharmacological inhibition of c-Raf, MEK1/2, and PI3K significantly $(P<0.05)$ reduced cell growth (Figure $2 B)$, IkB $\alpha$ phosphorylation (Ser32) and degradation (Figure 2C), and NF-KB activity (Figure 2D), indicating that both PI3Kand Ras-activating signaling pathways facilitated NF- $\mathrm{kB}$ activation. The effects of ILK have been widely studied because of its interactions with cell growth- and NF-kBassociated AKT $[4,9]$. Surprisingly, ILK silencing did not affect AKT and GSK-3 $\beta$ phosphorylation in the AGS and SNU-1 cells but markedly reduced c-Raf and ERK1/2 activation in all cells tested (Figure 2E; Additional file 5: Figure S4B). Without AKT deactivation, we evaluated an alternative pathway for activating NF- $\mathrm{kB}$ through a mechanism involving MAPK/p90RSK/IKB $\alpha$ signaling [38]. The knockdown of $I L K$ reduced the multiple phosphorylation

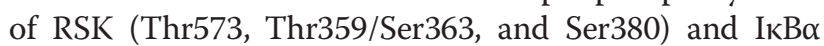
phosphorylation (Ser32) and increased I $\mathrm{K} B \alpha$ accumulation (Figure 2E). Inhibiting MEK1/2 caused similar effects (Additional file 5: Figure S4C) and a cell cycle arrest at the $\mathrm{G}_{1}$ phase (Additional file 5: Figure S4D). A Ras pulldown assay revealed that inhibiting ILK caused Ras deactivation without affecting the stability of the Ras protein (Figure 2F). These findings demonstrated a potential non-canonical pathway for ILK to modulate NF- $\mathrm{kB}$ by regulating Ras/c-Raf/MEK1/2/ERK1/2/IкB $\alpha$ signaling.
ILK can modify ERK1/2 activation under cell growth and differentiation [22]; however, the molecular regulation related to Ras signaling has not been documented $[2,3]$. The coexpression of ILK and phosphorylated ERK1/2 (Tyr202/Thr204) was demonstrated in human gastric tumors and AGS-derived nodules in BALB/c mice (Figure 2G). ILK interacts with IQGAP1 [7], a Ras GTPase-activating-like protein that is dissimilar from GAP, which transforms Ras to its inactive state. Because IQGAP1 controls Ras/MAPK signaling, it is oncogenic $[39,40]$. The expression of IQGAP family proteins was unchanged in the AGS and MKN45 cells, even after ILK silencing (Additional file 5: Figure S4E). However, silencing oncogenic IQGAP1, but not IQGAP3, (Additional file 5: Figure S4F-S4H) effectively inhibited c-Raf/ MEK1/2/ERK1/2/RSK signaling (Figure 2H), NF- $k B$ activity, and cell growth (Figure 2I). By performing a coimmunoprecipitation assay, we demonstrated a potential complex harboring ILK, IQGAP1, and Ras (Figure 2J). Immunostaining confirmed that ILK was coexpressed at levels similar to those of IQGAP1 and Ras (Figure 2K; Additional file 6: Figure S5). Notably, silencing ILK disrupted the IQGAP1-Ras complex (Figure 2L and 2M). These results demonstrated that ILK facilitated the formation of the IQGAP1-Ras complex to sustain Ras activity.

\section{Enzymatic ILK modulates the formation of the IQGAP1- Ras complex and ERK1/2-mediated cell growth}

Our findings showed that pharmacologically inhibiting ILK decreased cell growth, indicating the essential role of the enzymatic activity of ILK. Further inhibiting ILK by the genetic approach disrupted IQGAP1-mediated Ras signaling. Inhibiting ILK activity pharmacologically with T315 (Figure 3A) or genetically by transfecting the enzymatic mutant $\mathrm{ILK}_{\mathrm{A} 262 \mathrm{~V}}$ [41] (Figure 3B) also disrupted the formation of the IQGAP1-Ras complex in the AGS cells. Three truncated regions of ILK (Figure 3C) were overexpressed in the MKN45 cells to identify the domain essential for sustaining the IQGAP1-Ras complex. Coimmunoprecipitation assays demonstrated that overexpressed ILK constructs harboring PH and catalytic kinase domain regions immunoprecipitated with IQGAP1 and Ras (Figure 3D). Therefore, only kinase domain-containing ILK activated ERK1/2 (Figure 3E). Compared with the fulllength ILK (ILK $\left.{ }_{1-452}\right)$, transfecting the kinase-dead mutant ILK $_{\mathrm{A} 262 \mathrm{~V}}$ did not activate ERK1/2 (Figure 3F). Additional experiments demonstrated that only kinase domain-containing ILK increased MEK1/2-regulated NF- $k B$ activation (Figure 3G) followed by MEK1/2- and NF-kB-regulated cell growth (Figure $3 \mathrm{H}$ ) in the MKN45 cells. These results showed that enzymatic ILK mediated the formation of the IQGAP1-Ras complex to trigger ERK1/2- and NF-KB-mediated cell growth. 


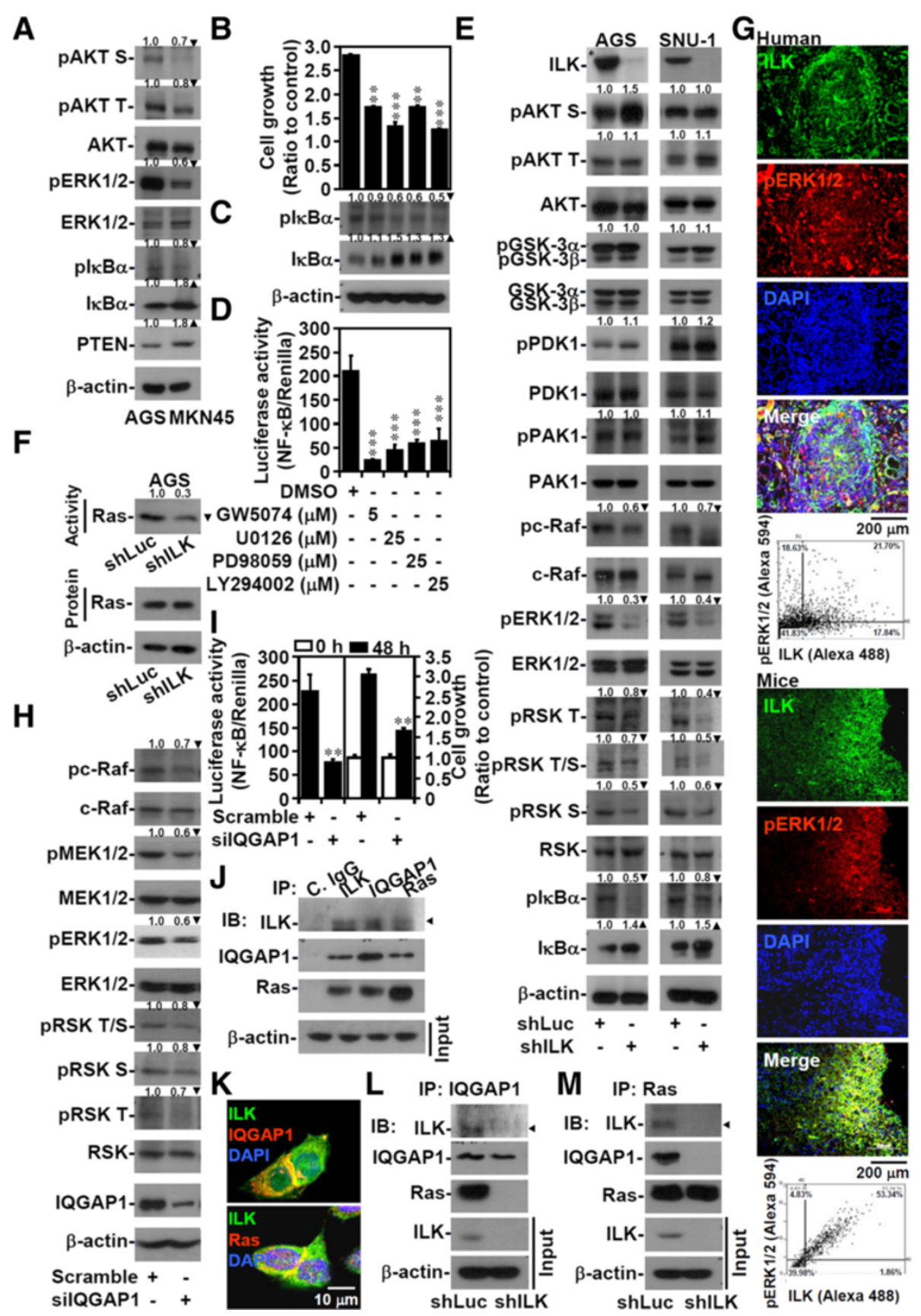

Figure 2 ILK-IQGAP1-Ras complex sustains Ras activity to activate c-Raf/MEK1/2/ERK1/2/RSK/IKBa/NF-KB signaling. (A) Western blot of the indicated proteins in AGS and MKN45 cells. $\beta$-actin was used as an internal control. AGS cells treated with c-Raf inhibitor GW5074, MEK1/2 inhibitors U0126 or PD98059, or PI3K inhibitor LY294002 for $48 \mathrm{~h}$ were evaluated for their growth (B), phosphorylation of IKBa at Ser32 (p/KBa) and total protein (C), and NF-KB activation (D). (E) In shLuc- or shlLK-transfected cells, western blots show the expression of the indicated proteins. $\beta$-actin was used as an internal control. (F) Ras activation assay showing Ras activity and protein expression in shLuc-and shlLK-transfected AGS cells. (G) Representative fluorescence-based immunohistochemical staining showing the coexpression of ILK (green) and phosphorylated ERK1/2 Tyr202/ Thr204 (red) in human gastric tumors and AGS-derived nodules in BALB/c mice. DAPI (blue) was used for nuclear counterstaining. The dot-plots show the coexpression of the indicated proteins. In control and IQGAP1 siRNA-transfected AGS cells at $48 \mathrm{~h}$, the expression of the indicated proteins (H), NF-KB activation, and cell growth (I) were shown. Protein lysates extracted from untreated AGS cells (J) or with shLuc and shlLK transfection (L, M) were immunoprecipitated (IP) with control IgG (C. IgG) or with antibodies against ILK, IQGAP1, and Ras. Immunoblots (IB) show the expression of ILK, IQGAP1, and Ras. (K) Representative fluorescence-based immunohistochemical staining showing the coexpression of ILK (green), IQGAP1 (red), and Ras (red) in AGS cells. DAPI (blue) was used for nuclear counterstaining. For proliferation and luciferase activity, data are mean \pm SD from three independent experiments. ${ }^{* *} P<0.01$ and ${ }^{* * *} P<0.001$ compared with control. Upright triangle, increased expression; inverted triangle, decreased expression. 


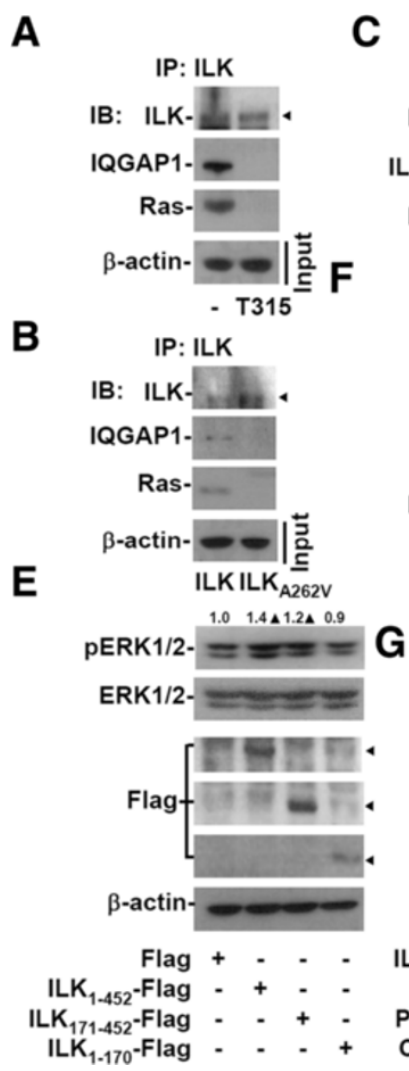

C
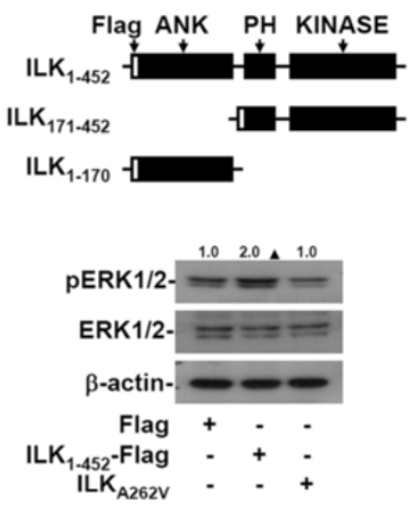

H

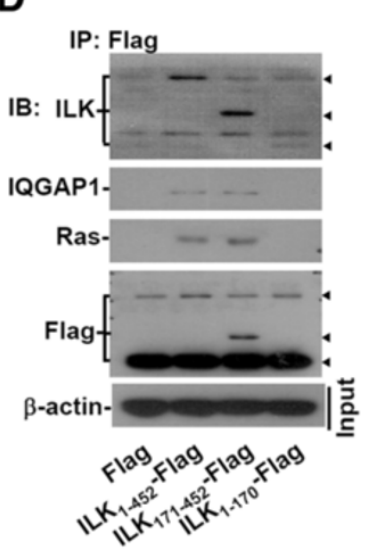

G

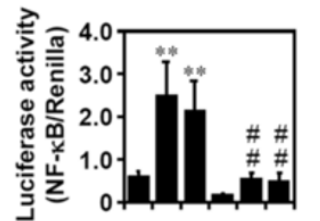

$\mathrm{Flag}+\ldots . \cdot-$

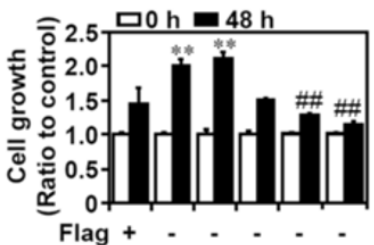

$\mathrm{ILK}_{1-452}$-Flag - + - + + $\mathrm{ILK}_{1-452}$-Flag - + - + +

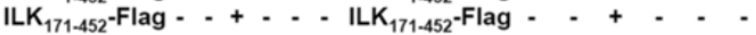

$\mathrm{ILK}_{1-170^{-}}$Flag - - + - - $\mathrm{ILK}_{1-170^{-}}$- $\mathrm{Flag} \cdot-++\cdots$

PD98059 $(\mu \mathrm{M})$ - - - 25 - PD98059 $(\mu \mathrm{M})$ - - - 25 -

CAPE $(\mu \mathrm{g} / \mathrm{ml})$ - - - - 25 CAPE $(\mu \mathrm{g} / \mathrm{ml})-\cdots \quad-\quad-25$

Figure 3 Enforced ILK expression facilitates cell growth by inducing ERK1/2/NF-KB activation. Protein lysates extracted from AGS cells treated

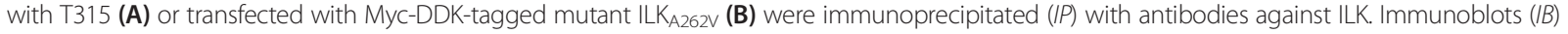
show the expression of ILK, IQGAP1, and Ras. Plasmids based on pCDNA3.1-Flag-ILK containing full-length ILK (ILK $1-452$ ), fragment 171-452 (ILK $171-452)$, fragment 1-170 (ILK $\left.K_{1-170}\right)(\mathbf{C})$, or Myc-DDK-tagged mutant ILK $K_{\text {A262V }}$ were transfected into MKN45 cells. (D) Coimmunoprecipitation of Flag with the indicated proteins is shown by using western blotting. Compared with pcDNA3.1-Flag (Flag) only, western blots show the expression of phosphorylated ERK1/2 at Tyr202/Thr204 (pERK1/2) (E, F). $\beta$-actin was used as an internal control. NF-KB activation (G) and cell growth (H) were also detected in the absence or presence of PD98059 and CAPE. Data are mean \pm SD from three independent experiments. ${ }^{*} P<0.01$ compared with control. \#\#P $<0.01$ compared with ILK $1-452$. Upright triangle, increased expression.

PI3K activation and decreased PTEN expression facilitate ERK1/2/NF-KB activation by stabilizing ILK

Because ILK is dependent on PI3K-mediated PIP3 generation for its activation [4], growth factor- and integrinmediated PI3K activation or a PI3K mutation in the AGS cells [37] could contribute to ILK expression and activation. Compared with the growth of the MKN45 cells, the growth of the AGS cells was unaffected by elevated IL- 6 levels [42], and the expression of $\beta 1$ and $\beta 3$ integrins did not increase (Additional file 7: Figure S6). We further confirmed that PIP3 generation was higher in the PI3K-mutated AGS cells (Figure 4A). To explore the relationships among the PI3K, ILK, and Ras signaling pathways, the AGS cells were treated with the MEK1/2, PI3K, ILK, or Ras inhibitor for different durations. At $6 \mathrm{~h}$ after treatment, T315 slightly inhibited MEK1/2 and ERK1/2 phosphorylation (Additional file 8: Figure S7). At $24 \mathrm{~h}$ after treatment, PI3K inhibition disrupted ILK expression, which was followed by MEK1/ 2/ERK1/2 deactivation $24 \mathrm{~h}$ after treatment (Figure 4B). However, Ras inhibition did not deactivate AKT or ILK in the AGS cells, although Ras can mediate PI3K activation [27]. Similar to the ILK-silenced AGS cells, both MKN45 and LY294002-stimulated AGS cells showed reduced Ras activity (Figure $4 \mathrm{C}$ ). The translation inhibitor cycloheximide facilitated LY294002-induced ILK downregulation (Figure 4D) and the proteasome inhibitor MG132 reversed the aforementioned effect and ERK1/2 inactivation (Figure 4E). The tumor suppressor phosphatase PTEN negatively regulates PI3K/PDK1/AKT signaling [10,11] and ILK activity $[8,9]$, and the AGS cells exhibited a low expression of PTEN (Figure 2A) [43]. The forced expression of PTEN in the AGS cells not only attenuated the constitutive phosphorylation of PDK1, AKT, and PAK1 but also inhibited ILK expression, ERK1/2 phosphorylation (Figure 4F), and NF-kB activation (Figure 4G). These 
A
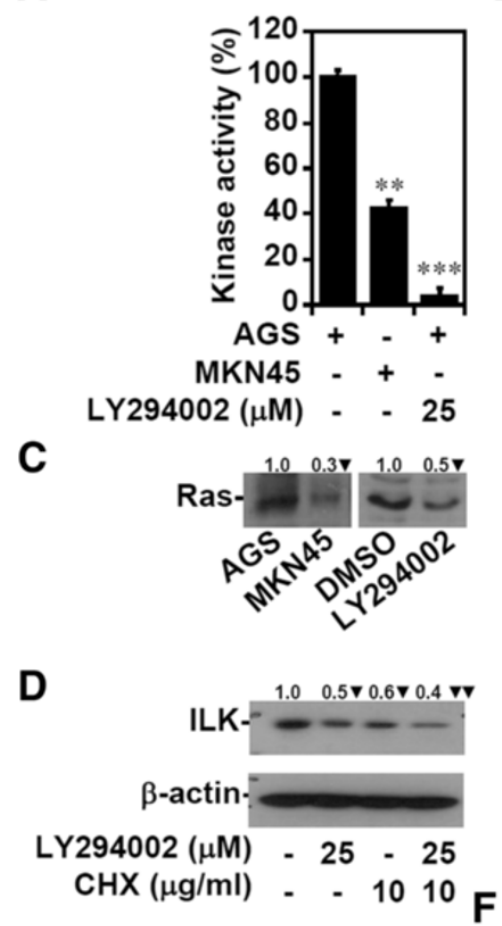

$\mathbf{E}$

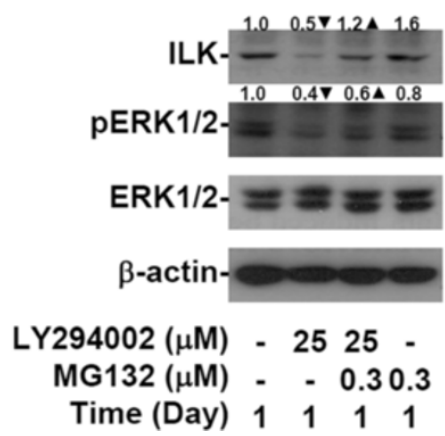

B

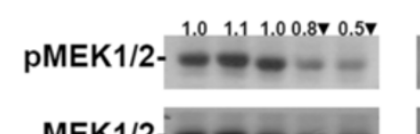

pERK1/2-1.0 $1.00 .3 \mathbf{v} 0.4 \mathbf{v} 0.2 \mathbf{v}$

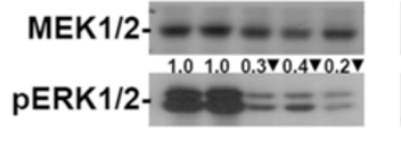

ERK1/2- $=2=$

pAKT S-

PAKT T- $=-$
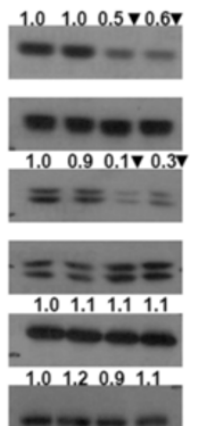

AKT-

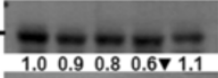

ILK- $-0--$

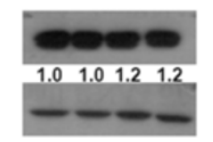

$\beta$-actin-

DMSO - + - - -

PD98059 $(\mu \mathrm{M})$ - - 25 -

LY294002 $(\mu \mathrm{M})$ - - - 25 -

T315 $(\mu \mathrm{M})-\quad-\quad-2.5$

FTI-277 $(\mu \mathrm{M})$ - $-\quad-\quad-$

Time (h) 2424242424

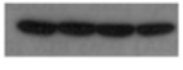

$-\cdot-\cdot$

$-\cdot-\cdot$

- - -

$-\cdot-\cdot$

10101010

$0 \quad 1624$

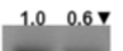

ILK-

pPDK1-

PDK1-

PAKT T-

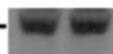

\section{(1)}

PERK1/2-

$1.0 \quad 0.6 \mathrm{~V}$

G

PAKT S- $=-$

$\mathrm{ERK} 1 / 2-==$
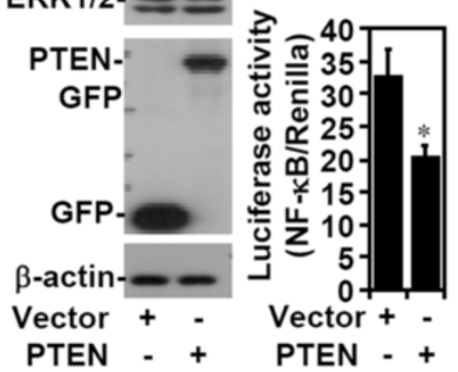

Figure 4 PI3K activation and decreased PTEN expression facilitate ERK1/2/NF-KB activation through ILK stabilization. (A) A PIP3 Mass ELISA Kit was used to determine PI3K activity by measuring the amount of PIP3 extracted from untreated AGS and MKN45 cells and from AGS cells treated with LY294002 for 24 h. (B) AGS cells were treated with PD98059, LY294002, T315, or Ras inhibitor FTI-277 for the indicated times. Western blots show the expression of the indicated proteins. $\beta$-actin was used as an internal control. (C) Ras activity was detected in AGS, MKN45, and LY294002-treated AGS cells after $24 \mathrm{~h}$. Western blots show the expression of the indicated proteins in AGS cells pretreated with the translation inhibitor cycloheximide (CHX) (D) or proteasome inhibitor MG132 (E) for $0.5 \mathrm{~h}$ and then treated with LY294002 for $24 \mathrm{~h}$. PTEN was overexpressed in AGS cells by using pCDNA3.1-GFP-PTEN (PTEN). Western blots show the expression of the indicated proteins compared with pcDNA3.1-GFP (Vector) transfection (F), and NF-KB activation (G) was also determined. For kinase and luciferase activity, data are mean \pm SD from three independent experiments. ${ }^{*} P<0.05$, ${ }^{*} P<0.01$, and ${ }^{* *} P<0.001$ compared with control. Upright triangle, increased expression; inverted triangle, decreased expression.

results indicated that PI3K activation and decreased PTEN expression stabilize ILK to regulate ERK1/2/NF$\kappa \mathrm{B}$ activation.

HSP90-associated E3 ligase CHIP negatively controls ILK stabilization, ERK1/2/NF-KB activation, and cell growth By further verifying the mechanism underlying ILK destabilization, our results showed that AKT inhibition did not affect ILK stability, whereas PI3K inhibition affected ILK stability (Additional file 9: Figure S8). HSP90 was next investigated because it can cause ILK degradation [25]. Similar to the results of PI3K inhibition, shRNA-based (Figure 5A) or pharmacological inhibition of HSP90 (Additional file 10: Figure S9A) delayed not only PDK1/AKT phosphorylation but also cRaf/MEK1/2/ERK1/2 activation after ILK degradation. 


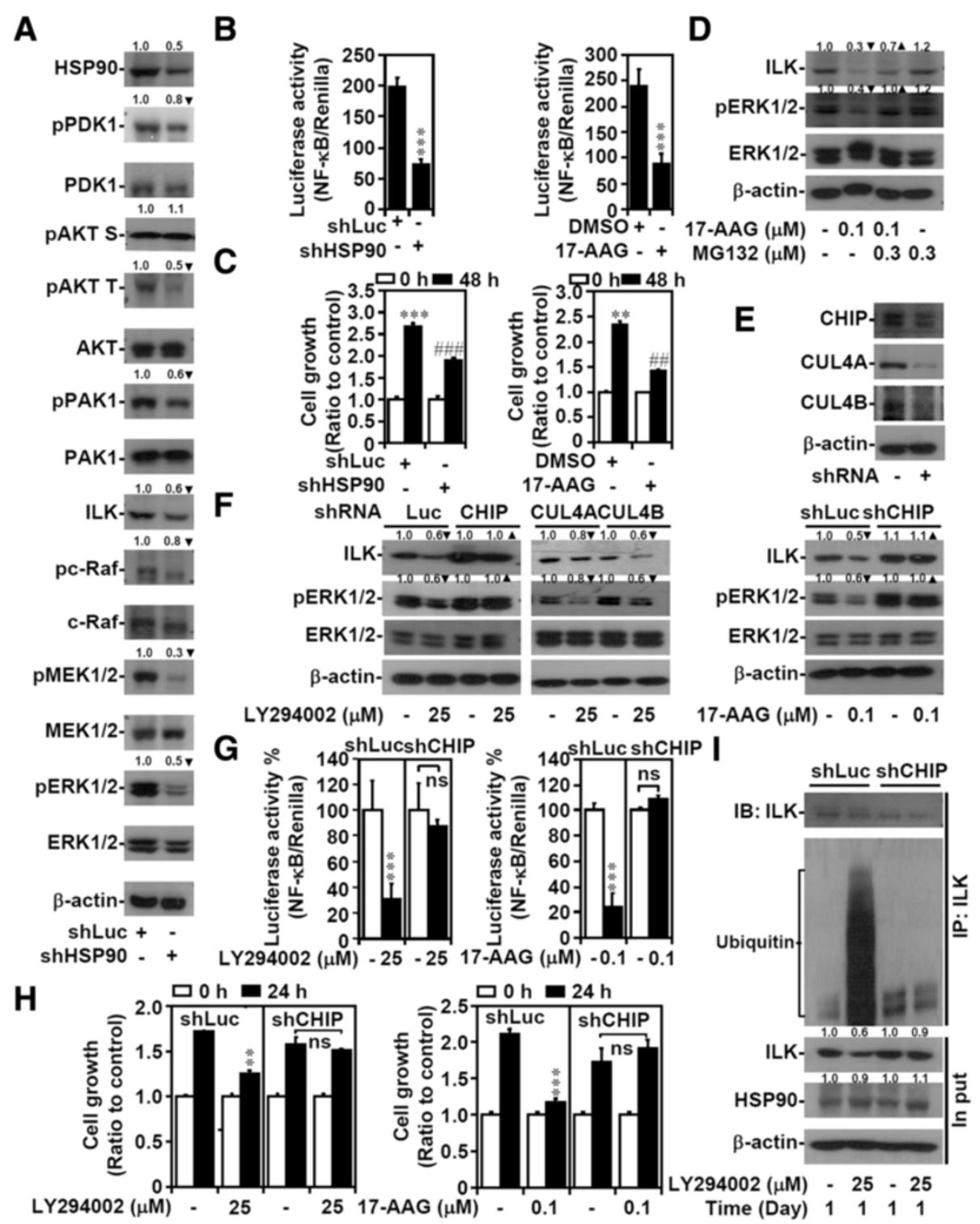

Figure 5 CHIP determines ILK destabilization, ERK1/2/NF-KB inactivation, and cell growth inhibition after PI3K/HSP90 inactivation. AGS cells were transfected with shLuc or shHSP90 or pretreated with the HSP90 inhibitor 17-AAG $(0.1 \mu \mathrm{M})$ for $48 \mathrm{~h}$. Western blots show the expression of the indicated proteins (A), and NF-KB activation (B) and cell growth (C) were also determined. (D) MG132 pretreatment (0.5 h) reversed ILK expression and phosphorylated ERK1/2 at Tyr202/Thr204 (pERK1/2) in 17-AAG-treated AGS cells. (E) CHIP, cullin 4A, and cullin 4B were silenced in AGS cells by shRNAs. shRNA-transfected cells were treated with LY294002 or 17-AAG for $24 \mathrm{~h}$. Western blotting showed the expression of ILK and phosphorylated ERK1/2 at Tyr202/Thr204 (pERK1/2) (F), and NF-KB activation (G) and cell growth (H) were also determined. (I) In shLuc- and shCHIP-transfected AGS cells treated with LY294002, ILK was immunoprecipitated, and its ubiquitylation was probed. For western blot analysis, $\beta$-actin was used as an internal control. For luciferase activity and cell growth, data are mean \pm SD from three independent experiments. ${ }^{* *} P<0.01$ and ${ }^{* * *} P<0.001$ compared with control. \#\#P<0.01 and \#\#P <0.001 compared with shLuc or DMSO. NS: not significant. Upright triangle, increased expression; inverted triangle, decreased expression.

Furthermore, genetically or pharmacologically inhibiting HSP90 by treatment with 17-AAG or the HDAC inhibitor SAHA, which traps HSP90 in an acetylated, enzymatically inactive state, attenuated NF- $\mathrm{KB}$ activity (Figure 5B; Additional file 10: Figure S9B) and cell growth (Figure 5C). Cotreatment with MG132 rescued the effects of 17-AAG (Figure 5D) and SAHA on ILK degradation and ERK1/2 inactivation (Additional file 10: Figure S9C). In the MKN45 cells, treatment with MG132 increased ILK expression, MEK1/2 and ERK1/2 phosphorylation (Additional file 11: Figure S10), and NF- $\mathrm{kB}$ activation (data not shown). Coimmunoprecipitation demonstrated the formation of the HSP90-ILK complex (data not shown). Using a lentiviral-based shRNA approach (Figure 5E), 
HSP90-associated E3 ligases, including CHIP, cullin 4A, and cullin $4 \mathrm{~B}[26,44,45]$, were examined for their roles in ILK degradation. The results showed that only silencing CHIP rescued ILK degradation and ERK1/2 inactivation (Figure 5F), NF-kB deactivation (Figure 5G), and cell growth inhibition (Figure $5 \mathrm{H}$ ) after the pharmacological inhibition of PI3K and HSP90. CHIP was required for ILK ubiquitination in the LY294002-treated AGS cells (Figure 5I). These results demonstrated that HSP90/ CHIP signaling regulates PI3K-mediated ILK stabilization and ILK-regulated ERK1/2/NF- $\mathrm{BB}$ activation and thus facilitates cell growth.

\section{PI3K/HSP90/CHIP/ILK/IQGAP1/ERK1/2/NF-KB signaling contributes to cell migration and sensitivity to 5-FU and cisplatin}

Increased ILK activity or expression could regulate oncogenic processes, including cell proliferation, migration, and survival $[3,6]$. We studied the potential involvement of the identified PI3K/HSP90/CHIP/ILK/IQGAP1/ ERK1/2/NF- $\mathrm{B}$ signaling pathway in cell growth advantages. Compared with the MKN45 cells, the AGS cells showed increased migratory activity; however, ILK or IQGAP1 silencing significantly $(P<0.001)$ abolished cell migration (Additional file 12: Figure S11A). Pharmacologically blocking PI3K/HSP90/ILK/MEK1/2/NF-кB signaling in the AGS cells also significantly $(P<0.001)$ attenuated the migratory ability (Additional file 12: Figure S11B), and CHIP knockdown considerably reversed the inhibitory effects caused by the inhibition of PI3K and HSP90 (Figure 6A; Additional file 12: Figure $\mathrm{S} 11 \mathrm{C})$. The anticancer agents 5 -FU and cisplatin are commonly used in the treatment of gastric cancers [46]. Treating the AGS cells with 5-FU or cisplatin, particularly after ILK or IQGAP1 silencing, caused increased susceptibility to apoptosis (Figure 6B). T315 increased the sensitivity of the AGS cells to 5-FU and cisplatin (Additional file 12: Figure S11D). Pharmacologically inhibiting PI3K/HSP90/ILK/MEK1/2/NF- $\mathrm{B}$ signaling also sensitized the AGS cells to 5-FU-induced apoptosis (Figure 6C), whereas CHIP silencing retarded the synergistic effects of LY294002 and 17-AAG on 5-FUinduced apoptosis (Figure 6D). In contrast, the overexpression of ILK containing a catalytic kinase domain, including ILK $_{1-452}$ and ILK $_{171-452}$, enhanced MEK1/2/NF-kB-regulated cell migration (Figure $6 \mathrm{E}$ ) and cell survival after treatment with 5-FU (Figure 6F). These results indicated the common effects of ILK and IQGAP1 on ERK1/2/NF-kB activation for cell migration and survival.

\section{EGFR signaling regulates ILK/IQGAP1 to activate ERK1/2,} NF- $\mathrm{KB}$, and cell migration and proliferation

To verify the role of ILK/IQGAP1-mediated ERK1/2 and NF- $\kappa \mathrm{B}$ activation, we examined EGF/EGFR signaling as previously described $[47,48]$. ILK or IQGAP1 silencing partially eliminated the exogenous EGF-induced ERK1/2 and AKT phosphorylation in the AGS (Figure 7A) and A549 cells (Additional file 13: Figure S12A). However, IQGAP1 silencing attenuated EGF-activated ERK1/2 but not EGF-activated AKT, suggesting an IQGAP1independent AKT activation. ERK1/2 phosphorylation through multiple stimuli, including hydrogen peroxide (Additional file 13: Figure S12B) and Helicobacter pylori infection (Additional file 13: Figure S12C) [49-51], was also abolished in the ILK-silenced cells. Silencing ILK or IQGAP1 caused a significant $(P<0.001)$ decrease in EGF-induced NF- $\mathrm{KB}$ activation (Figure $7 \mathrm{~B}$ ), and cell growth (Figure 7C) and migration (Figure 7D). The wild-type and the constitutively active form of EGFR mutated at domain VIII $[48,52]$ were transfected into the MKN45 cells, which were then treated with or without EGF. ILK overexpression was accompanied by ERK1/2 and AKT activation; however, inhibiting PI3K and HSP90 decreased not only ILK expression but also ERK1/2 and AKT activation (Figure 7E). These findings demonstrated that both ILK and IQGAP1 are required for EGF/EGFR-triggered ERK1/2/NF- $\mathrm{B}$ activation and cell growth advantages and that ILK expression can be positively regulated by EGF/EGFR/PI3K/HSP90 signaling.

\section{Discussion}

By using genetic and pharmacological approaches, we confirmed the proliferation-promoting role of ILK in vitro in gastric cancer cells. The function of ILK is highly related to NF- $\mathrm{kB}$ activation. An in vivo model of gastric cancer in mice showed the essential role of ILK in tumor growth [34], and increased ILK [28] and NF-кB [35] activity or expression is related to gastric tumorigenesis. Although the potent mechanisms for ILK-regulated cell proliferation have been previously documented [6], we further investigated the molecular basis of ILK-mediated gastric cancer cell growth, which is related to NF- $\mathrm{kB}$ activation. To the best of our knowledge, clinical observations in this study indicated a positive correlation between ILK expression, NF- $\mathrm{kB}$ activation, and cell proliferation in gastric cancers. Protection from apoptosis [13] and the stimulation of cell proliferation are oncogenic effects of ILK that are generally achieved by facilitating NF- $\mathrm{B}$ activation. Based on these rationales, the molecular regulation of the ILK/NF- $\mathrm{KB}$ pathway was examined. According to the present study results (summarized in Figure 8), increased ILK activity or expression, which is controlled by PI3K/HSP90-mediated protein stabilization, triggers a non-canonical pathway of IQGAP/Ras/c-Raf/MEK1/2/ ERK1/2/RSK/NF-kB signaling to stimulate cell growth, migration, and survival.

Aberrant ILK is involved in tumorigenesis, and it is speculated that ILK canonically stimulates AKT to promote 


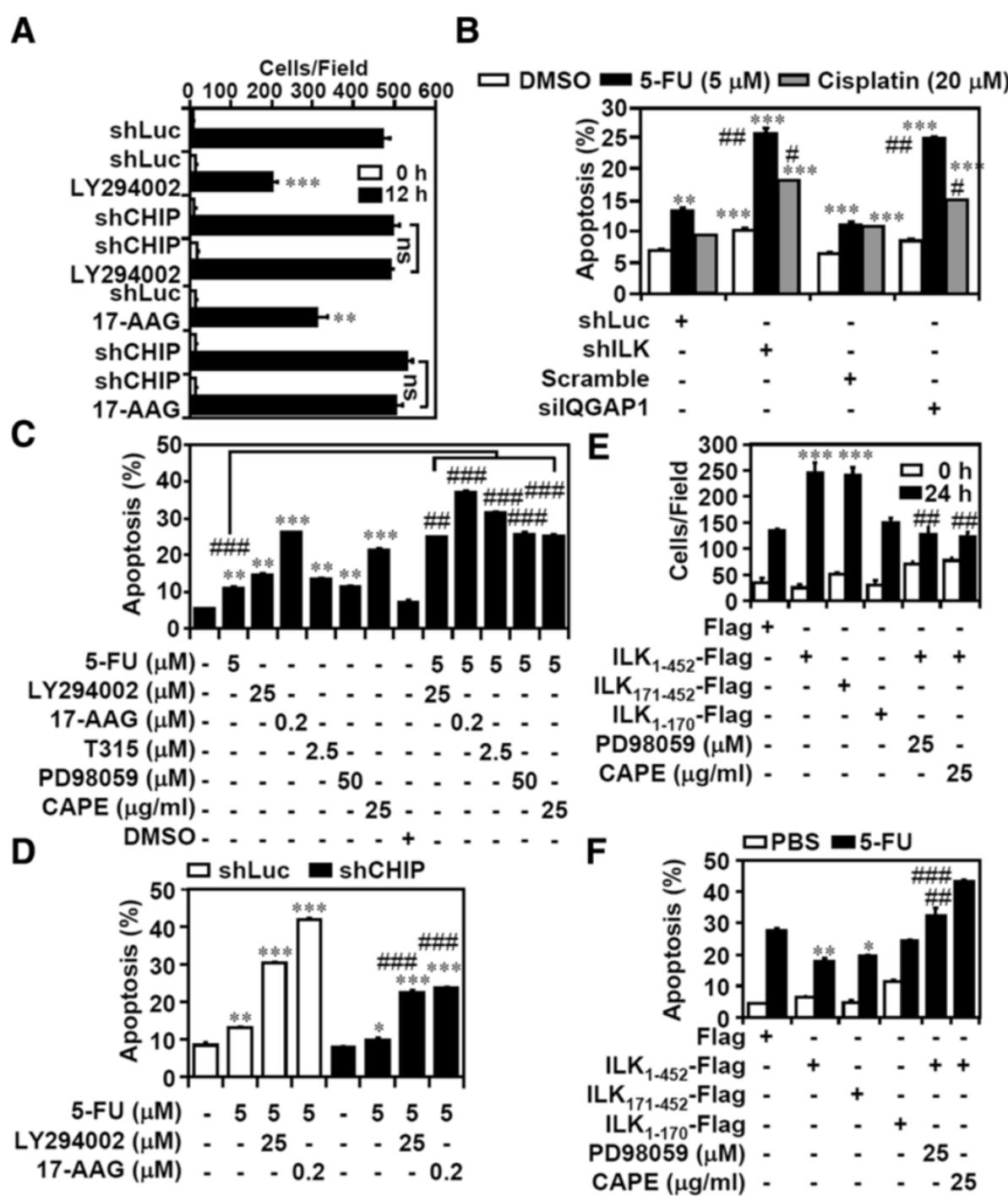

Figure $6 \mathrm{PI3K} / \mathrm{HSP90/CHIP/ILK/ERK1/2/NF-KB} \mathrm{signaling} \mathrm{determines} \mathrm{cell} \mathrm{migration} \mathrm{and} \mathrm{controls} \mathrm{susceptibility} \mathrm{to} \mathrm{the} \mathrm{anticancer} \mathrm{agents}$ 5-FU and cisplatin. (A) Migration activity was tested in shLuc- or shCHIP-transfected AGS cells treated with LY294002 (25 HM) and 17-AAG $(0.2 \mu \mathrm{M})$ for $12 \mathrm{~h}$. shLuc, control siRNA, or DMSO were used as negative controls. The numbers of migrated cells in the observed field are shown. PI staining followed by flow cytometry analysis showed 5-FU- or cisplatin-induced apoptosis for 2 days in shILK- or silQGAP1-transfected AGS cells (B), AGS cells pretreated with the indicated inhibitors for $0.5 \mathrm{~h}$ (C), and shLuc- or shCHIP-transfected AGS cells treated with LY294002 or 17-AAG (D). shLuc, control siRNA, or DMSO were used as negative controls. Plasmids based on pcDNA3.1-Flag-ILK containing full-length ILK (ILK $1-452$ ), fragment 171-452 (ILK $171-452)$, or fragment 1-170 (ILK $1-170)$ were transfected into MKN45 cells. Compared with pcDNA3.1-Flag (Flag) only, cell migration (E) and apoptosis induced by 5-FU $(5 \mu \mathrm{M})(\mathbf{F})$ were detected in the absence or presence of PD98059 and CAPE. Data are mean \pm SD from three independent experiments. ${ }^{*} P<0.05$, ${ }^{* *} P<0.01$ and ${ }^{* * *} P<0.001$ compared with control. $\# P<0.05$, \#\#P<0.01, and \#\#\#P<0.001 compared with control. NS: not significant.

NF- $k B$-mediated oncogenic processes, such as antiapoptosis [13] and survival [14]. In tumorigenesis, NF$\mathrm{KB}$ can promote survival and proliferation, angiogenesis, adhesion/invasion/metastasis, and inflammation. However, the mechanisms underlying NF- $\mathrm{KB}$ activation in cancer cells are multifaceted; both AKT and MAPKs are crucial for NF-kB activation [38]. Of note, AGS cells have mutated PIK3CA and KRAS [37]. Inhibiting PI3K and Ras activity attenuated NF- $\mathrm{B}$ activation. We therefore hypothesized a role for ILK to canonically or non-canonically act upstream of AKT and ERK1/2, respectively. ILK-mediated AKT phosphorylation at Ser473 was confirmed in lung adenocarcinoma A549 cells but not in gastric cancer cells. Surprisingly, ILK silencing effectively negatively affected ERK1/2 activation in all cells tested. In addition to the kinase activity of ILK, scaffold functions of ILK associated with intracellular molecules also need further investigation to verify its roles in regulating AKT and ERK1/2 signaling. 


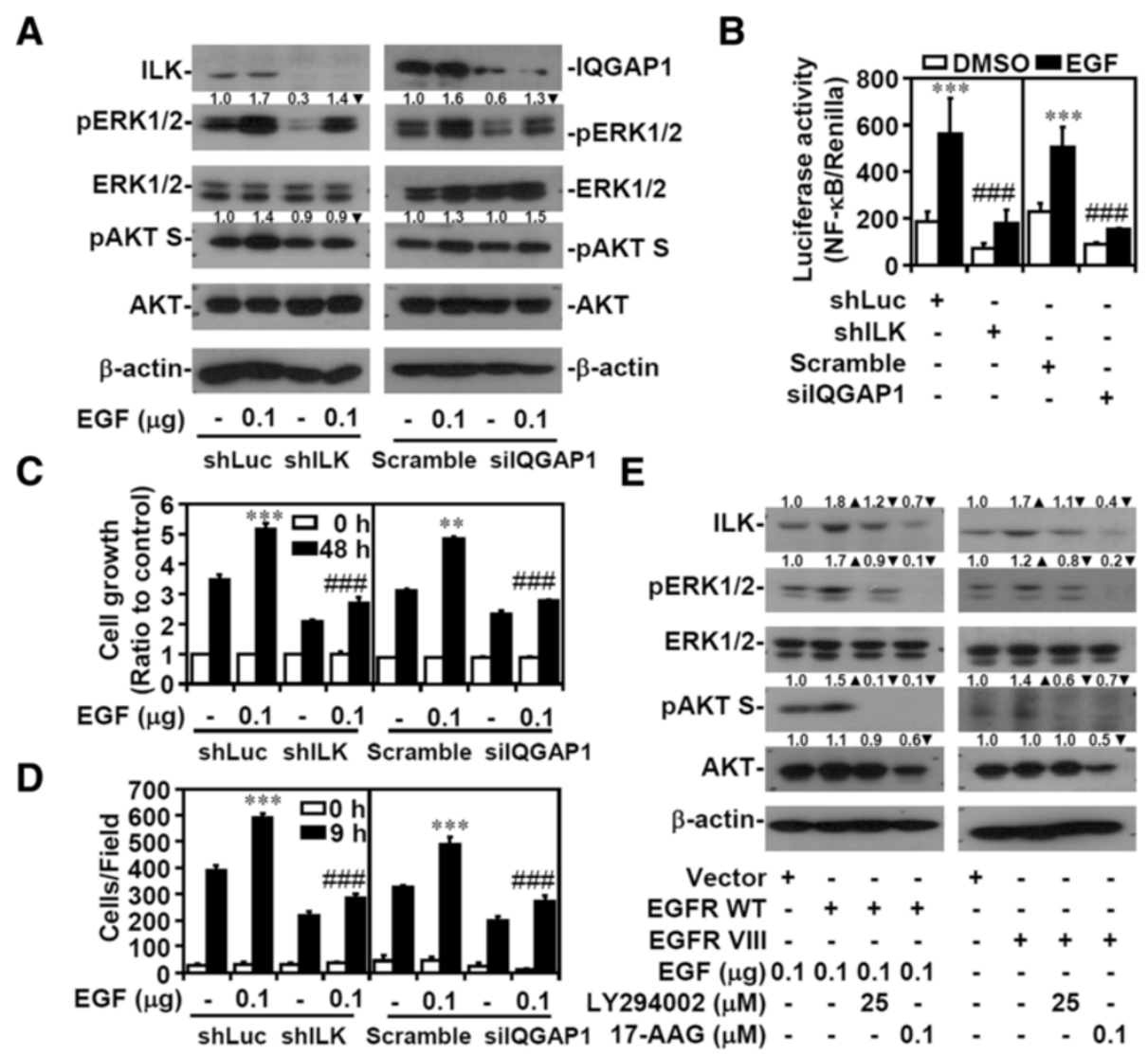

Figure 7 ILK and IQGAP1 facilitate EGF/EGFR-induced NF-KB activation and cell growth and migration, and activated EGFR increases ILK expression. (A) Western blots showing ERK1/2 phosphorylation at Tyr202/Thr204 (pERK1/2) and AKT phosphorylation at Ser473 (pAKT S) in shILK- or silQGAP1-transfected AGS cells treated with EGF for $1 \mathrm{~h}$. shLuc and control siRNA were used as negative controls. $\beta$-actin was used as an internal control. Furthermore, in these cells, NF-KB activation (B), cell growth (C), and migration (D) were detected. Data are mean \pm SD from three independent experiments. ${ }^{* *} P<0.01$ and ${ }^{* *} P<0.001$ compared with negative control. \#\#\#P<0.001 compared with shLuc or control siRNA. (E) In EGFR WT-transfected and EGFR VIII-transfected MKN45 cells treated with or without EGF for $1 \mathrm{~h}$ plus LY294002 or 17-AAG $24 \mathrm{~h}$ posttreatment, western blots show the expression of ILK, phosphorylated ERK1/2 at Tyr202/Thr204 (pERK1/2), and phosphorylated AKT at Ser473 (pAKT S). $\beta$-actin was used as an internal control. Upright triangle, increased expression; inverted triangle, decreased expression.

ERK1/2 mediates NF-KB activation through a mechanism involving MAPK/p90RSK/IкB $\alpha$ signaling [38]; similarly, we demonstrated that this pathway was required for ILKmediated NF- $\mathrm{kB}$ activation in gastric cancer cells. ILK has a possible upstream role in ERK1/2 activation [16,22,23,48], but no rational mechanisms exist for examining this regulation $[2,3]$.

An emerging and widely demonstrated role for IQGAP1 is its control over diverse biological functions by interacting with various cellular factors [53]. For MAPK signaling, IQGAP1 can directly regulate Ras/ERK1/2 activation during tumorigenesis [39,40]. Ras is a small GTPase that can hydrolyze GTP into GDP in a GTP-bound protein to inactivate the protein, a process accelerated by GAPs, and this process can be reversed with a guanine nucleotide exchange factor to reactivate the Raf/MAPK pathway [27]. IQGAP is a Rho-GTP-binding protein and has a region similar to that of Ras GAP. However, IQGAP has no GAP function but can stabilize the GTP-bound protein in an activated state $[54,55]$. A global analysis of the ILK interactome has shown a strong ILK-IQGAP1 interaction [7]; however, no studies have illustrated the axis of ILK/ IQGAP1/Ras signaling. Wickstrom et al. demonstrated an ILK-IQGAP1 association through the non-ANK repeats of ILK and the IQ motif of IQGAP1 for facilitating integrin signaling [56]. To our knowledge, the present study is the first to show that increased or decreased activity or expression of ILK did not affect IQGAP1 expression, although silencing ILK disrupted the IQGAP1-Ras interaction. These three proteins formed a novel complex around the cell membrane, particularly in cell-cell junctions. Regarding IQGAP1 sustaining Ras activity in gastric cancer cells, IQGAP1 but not IQGAP3 mediated cell growth through an ERK1/2-regulated NF- $\mathrm{kB}$ activation pathway. The present study reveals a novel axis of ILK/ IQGAP1 for Ras/ERK1/2 signaling; however its cellular 


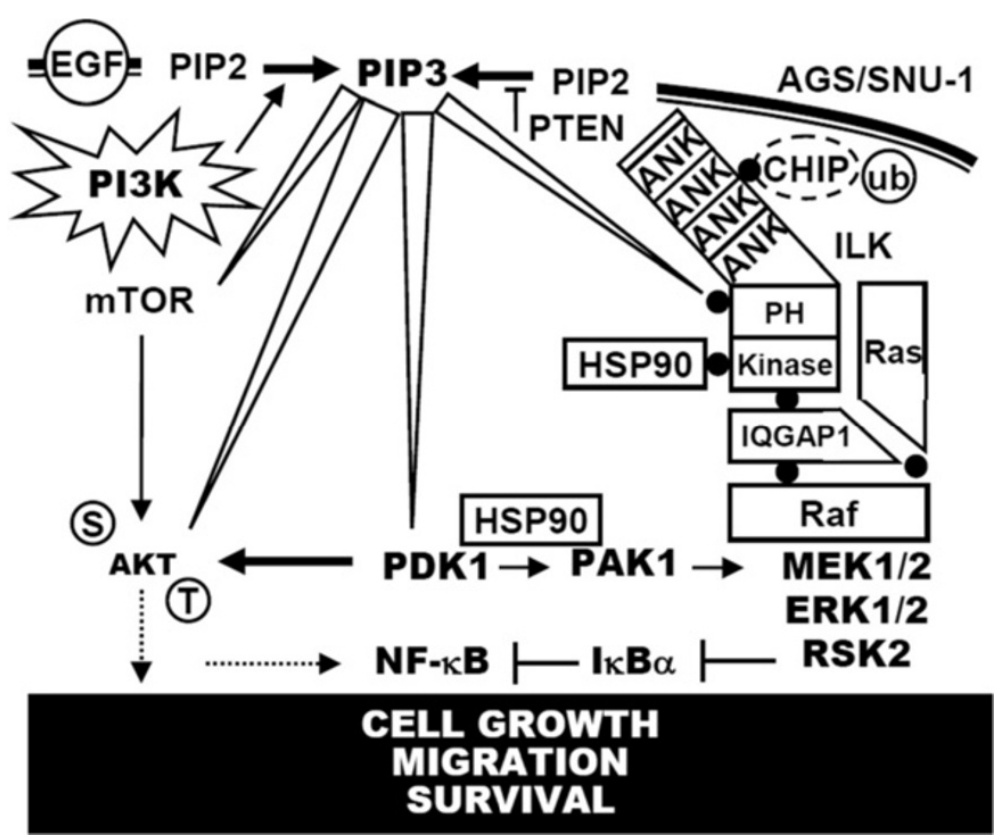

Figure 8 A hypothetical model for PI3K/HSP90-regulated ILK, followed by ILK-mediated IQGAP1/Ras/C-Raf/MEK1/2/ERK1/2/RSK/NF-KB activation in cell growth, migration, and survival

significance requires further investigation. The abnormal expression of IQGAP1 is related to poor prognosis in gastric cancers [57]. The formation of an ILK-IQGAP1 complex may have multiple biological effects; IQGAP1 has been implicated in diverse cellular functions through a mechanism involving the interaction of cytoskeletal components, small GTPases, kinases, and receptors [53].

Besides using the genetic approach, pharmacologically inhibiting ILK with T315 or an ILK kinase-dead mutation $\left(\right.$ ILK $\left._{\mathrm{A} 262 \mathrm{~V}}\right)$ abolished the IQGAP1-Ras interaction and thus deactivated ERK1/2. The enzymatic activity of ILK is speculated to be crucial for the axis of ILK/ IQGAP1/Ras signaling. Further results showed the importance of the PH-like domain and the kinase domain in mediating the formation of ILK/IQGAP1 complex as well as ERK1/2 activation, NF- $\mathrm{KB}$ activation, and cell growth. The mechanism underlying the ILK-mediated IQGAP1-Ras interaction is unknown; ILK phosphorylates its substrates as well as acts as an adaptor for protein-protein interactions $[2,3]$. Together with the findings that the non-ANK repeats of ILK are required for binding with the IQ domain of IQGAP1 [53,56], it is reasonable to hypothesize that ILK initiates the phosphorylation of the IQGAP1-Ras complex and/or that ILK confers an adaptor-mediated interaction for this complex.

Although increased ILK expression contributes to tumorigenesis, the mechanisms for ILK overexpression remain unknown. ILK upregulation and activation are related to $\beta 1$ integrin signaling [1], and integrins may regulate gastric tumorigenesis, particularly by modulating adhesion and metastasis [58,59]. Thus, integrin overexpression causes ILK upregulation and activation. However, in the gastric cancer cell lines AGS and MKN45 that we tested, there were no differences in the expression or activation of $\beta 1$ or $\beta 3$ integrin. In addition to integrin signaling, growth factors generally activate PI3K for cell growth advantages. The expression of cell growth-associated IL-6 is higher in the AGS cells than in the MKN45 cells; however, its potential role in gastric cancer cell proliferation has been excluded. In addition to PIK3CA mutations [37], growth factors involved in regulating ILK expression need further investigation.

Surprisingly, pharmacologically inhibiting PI3K decreased ILK expression along with ERK1/2 deactivation. This result indicates an upstream role for PI3K-regulated ILK stabilization linked to Ras/ERK1/2 signaling. In the AGS cells, ILK overexpression may result from a natural mutation in PIK3CA that generates PIP3 to stabilize ILK expression. The most important finding in this study is the mechanism of ILK-dependent ERK1/2 activation demonstrated in the AGS cells, although these cells harbor PI3CA and KRAS mutations [37]. ILK may be required to sustain Ras activity, although Ras is automatically activated. The PH-like domain is essential for ILK to interact with PIP3 [4]. Once PI3K-driven PIP3 generation mediates ILK recruitment, ILK signaling can be initiated after protein stabilization. It is speculated that aberrant PI3K activation can cause ILK upregulation. The level of PTEN, a tumor suppressor related to PIP3 downregulation, is markedly decreased in several cancers, including 
gastric cancers. Restoring PTEN expression in the AGS cells effectively abolished both AKT and ERK activation and decreased ILK expression. PI3K/PTEN/PIP3-mediated ILK stabilization is therefore important for ERK1/ 2 activation.

PDK1 activates PAK1 [60], and PAK1 phosphorylates ILK [61]. Here, the pharmacological inhibition of PI3K inhibited PDK1 and PAK1 activation (Additional file 14: Figure S13A); however, PAK1 knockdown did not alter ILK expression but decreased c-Raf/ERK1/2 phosphorylation, NF- $\mathrm{kB}$ activation, and cell growth (Additional file 14: Figure S13B-13D). These results indicated that PI3Kcontrolled PAK1 does not contribute to ILK expression. HSP90 is a chaperone that associates with client proteins [62-65]. HSP90 regulates ILK stability [25] through an interaction at amino acids 377-406 within the kinase domain of ILK. HSP90 can maintain the tumor-like character of rheumatoid synovial cells by stabilizing ILK, ERK, and AKT [16]. However, the potential regulation of ILK/ERK/ AKT signaling by HSP90 remains undetermined. Our study further demonstrated that the HSP90-associated E3 ligase CHIP was required for ILK stabilization, whereas inhibiting PI3K and HSP90 caused CHIP-proteasomemediated ILK degradation. Radovanac et al. demonstrated that ILK stability is negatively regulated by CHIP ubiquitination in fibroblasts when HSP90 is inhibited [26]. The molecular stabilization of ILK by HSP90 and CHIP remains unclear, but HSP90 interacts with the kinase domain of ILK $[25,26]$, and CHIP-mediated ubiquitylation occurs at the ANK repeats of ILK [26]. CHIP regulates ILK stability in conjunction with others, and this regulation is important for ILK-regulated ERK1/2 and NF-KB activation and cell growth. Regarding the multiple oncogenic effects of ILK, the results of this study and those of previous studies reveal the molecular mechanism of ILK stabilization and expression; furthermore, we showed that ILK promotes cancer cell growth, migration, and survival responses through ERK1/2-regulated NF-кB activation.

The limitation of this study is that the changes observed were in the AGS cells, which have PIK3CA and KRAS mutations [37] and decreased PTEN expression. To confirm the finding that ILK facilitates ERK1/2 activation in response to physiological and pathological stimuli, we showed that hydrogen peroxide and $H$. pylori infection caused ILK-regulated ERK1/2 activation. In addition, the exogenous administration of EGF confirmed the requirement of ILK and IQGAP1 in EGF-induced ERK1/2 activation, NF- $k B$ activation, cell growth, and migration $[47,48]$. Crosstalk between EGFR and integrins facilitates gastric cancer cell invasion and proliferation [66]. Moreover, the overexpression of WT EGFR and EGFR mutated at domain VIII may induce PI3K/HSP90-regulated ILK stabilization followed by ERK1/2 activation [48,52]. Regarding the critical role of Ras/ERK1/2 in cell growth advantages [27], the aforementioned results elucidate the significance of ILK in cell growth advantages, at least in gastric cancers, through a non-canonical mechanism involving the facilitation of ERK1/2 activation.

\section{Conclusion}

Based on the finding that PI3K/PTEN/HSP90-regulated ILK upregulation induces non-canonical IQGAP1/Ras/ ERK1/2-mediated NF- $\mathrm{B}$ activation and growth advantages in gastric cancer cells, targeting this pathway may be beneficial when used in combination with other anticancer agents. Our hypothesis requires further in vivo investigation with an appropriate animal model.

\section{Materials}

\section{Chemicals and antibodies}

The ILK inhibitor T315 was a gift from Dr. Ching-Shih Chen, College of Pharmacy, The Ohio State University [36]. The NF-KB inhibitor caffeic acid phenethyl ester (CAPE); c-Raf inhibitor GW5074; MEK inhibitors U0126 and PD98059; PI3K inhibitor 2-(4-morpholinyl)-8-phenyl4H-1-benzopyran-4-one hydrochloride (LY294002); translation inhibitor cycloheximide; proteasome inhibitor MG132; Ras inhibitor FTI-277; HSP90 inhibitor 17-AAG; 5fluorouracil (5-FU); cisplatin; dimethyl sulfoxide (DMSO); 4,6-diamidino-2-phenylindole (DAPI); and propidium iodide (PI) were purchased from Sigma-Aldrich (St. Louis, MO, USA). Antibodies against phosphorylated AKT at Ser473 (pAKT S), phosphorylated AKT at Thr308 (pAKT T), AKT, phosphorylated GSK-3 $\alpha / \beta$ at Ser21/Ser9 (pGSK$3 \alpha / \beta)$, GSK-3 $\alpha / \beta$, phosphorylated PDK1 at Ser241 (pPDK1), PDK1, phosphorylated PAK1 at Thr423 (pPAK1), PAK1, phosphorylated c-Raf at Ser338 (pc-Raf), c-Raf, phosphorylated MEK1/2 at Ser217/Ser221 (pMEK1/2), MEK1/2, phosphorylated ERK1/2 at Thr202/Tyr204 (pERK1/2), ERK1/2, phosphorylated p90RSK at Thr573 (pRSK T), phosphorylated p90RSK at Thr359/Ser363 (pRSK T/S), phosphorylated p90RSK at Ser380 (pRSK S), RSK, phos-

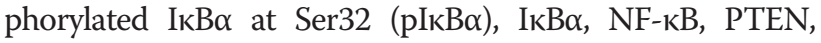
HSP90, CHIP, cullin-4A/4B, ubiquitin, and anti-EGFP were purchased from Cell Signaling Technology (Beverly, MA, USA). Anti-ILK, anti-phosphorylated NF- $\mathrm{KB}$ at Ser536 (pNF-кB), anti-Ras, and anti-IQGAP1, anti-IQGAP2, and anti-IQGAP3 antibodies were purchased from Santa Cruz Biotechnology (Santa Cruz, CA, USA). Antibodies against $\mathrm{Ki}-67$ and NF- $\mathrm{KB}$ were purchased from Abcam (Cambridge, MA, USA). Mouse monoclonal antibodies specific for $\beta$-actin and FLAG were purchased from Chemicon International (Temecula, CA, USA). Alexa Fluor 488- and horseradish peroxidase (HRP)-conjugated goat anti-mouse, goat anti-rabbit, and donkey anti-goat IgG antibodies were purchased from Invitrogen (Carlsbad, CA, USA). Cytotoxicity assays were performed to assess drug toxicities before the 
experiments; non-cytotoxic doses were used in this study.

\section{Gastric cancer specimens}

In this study, 150 cores, including reactive and cancerous (different grades and stages) tissues of the stomach, were obtained from a commercial tissue microarray (BioChain Institute, Inc., Hayward, CA, USA) built for immunohistochemical interrogation. AGS-derived gastric nodules in BALB/c mice were accordingly arrayed [67]. For animal studies, 6- to 8-week-old male wild-type $\mathrm{BALB} / \mathrm{c}$ mice were purchased from Jackson Laboratory (Bar Harbor, ME, USA) and fed standard laboratory food in the Laboratory Animal Center of National Cheng Kung University. The animals were raised and handled according to the guidelines established by the National Science Council, Taiwan. The experimental protocols adhered to the rules of the Animal Protection Act of Taiwan and were approved by the Laboratory Animal Care and Use Committee of National Cheng Kung University.

\section{Cell lines and cell culture}

AGS (CRL-1739, ATCC; derived from a biopsy specimen of an untreated human gastric adenocarcinoma harboring KRAS, PIK3CA, CDH1, and CTNNB1 mutations), metastatic MKN45 (JCRB0254, The RIKEN Cell Bank, Japan; established from a poorly differentiated adenocarcinoma of the medullary type from the stomach of a 62 year-old woman bearing an E-cadherin mutation), and SNU-1 human gastric adenocarcinoma cells (CRL-5971, ATCC; derived from a metastatic ascites site of a poorly differentiated primary stomach carcinoma harboring KRAS and MLH1 mutations), and GES-1 gastric epithelial immortalized cells, kindly provided by Dr. Pei-Jung Lu, National Cheng Kung University, were routinely grown in plastic cell culture dishes in Ham's F-12 nutrient mixture, DMEM, or RPMI 1640 (F-12, RPMI; Invitrogen Life Technologies, Rockville, MD, USA) with L-glutamine and $15 \mathrm{mM}$ HEPES supplemented with 10\% heat-inactivated fetal bovine serum (FBS; Invitrogen Life Technologies), 50 units of penicillin, and $50 \mu \mathrm{g} / \mathrm{mL}$ of streptomycin and maintained in a humidified atmosphere with $5 \% \mathrm{CO}_{2}$ and $95 \%$ air.

\section{Immunohistochemical/immunocytochemical staining}

Tissue blocks were fixed overnight at $4^{\circ} \mathrm{C}$ with $4 \%$ neutral buffered paraformaldehyde solution, dehydrated, cleared with HistoClear II (National Diagnostics, Atlanta, GA, USA), and embedded in wax. For immunohistochemical staining, tissue sections were deparaffinized, rehydrated, incubated with $3 \% \mathrm{H}_{2} \mathrm{O}_{2}$ in methanol for $15 \mathrm{~min}$, and subjected to heat-induced antigen retrieval by boiling for $10 \mathrm{~min}$ in $0.01 \mathrm{M}$ citric acid. For immunocytochemical staining, cells were fixed in 3.7\% formaldehyde in PBS for $10 \mathrm{~min}$. After washing twice with PBS, the tissue sections and cells were mixed with primary antibodies in antibody diluents (Dako Corporation, Carpinteria, CA, USA) and incubated overnight at $4^{\circ} \mathrm{C}$. The following day, samples were washed with PBS and incubated with or without HRP- or fluorescence-labeled secondary antibodies at room temperature for $1 \mathrm{~h}$. For immunohistochemistry, antibodies against ILK, Ki-67, pNF-kB, NF-kB, and pERK1/2 were used. HRP-reactive sections were washed with PBS, developed with an AEC substrate, counterstained with hematoxylin, and visualized using a microscope (IX71; Olympus, Tokyo, Japan). For confocal microscopy, DAPI $(5 \mu \mathrm{g} / \mathrm{mL})$ was used for nuclear staining. The sections were then visualized using a confocal laser scanning microscope (Digital Eclipse C1si-ready; Nikon, Tokyo, Japan). We alternatively used the TissueFAXS system (TissueGnostics, Vienna, Austria) to analyze the immunostaining of the tissues. In HistoQuest software (TissueGnostics, Tarzana, CA, USA), we plotted the $\mathrm{X}$ and $\mathrm{Y}$ axes for the expression of the indicated proteins. Therefore, the upper-right region of dot-plot shows double-positive expression but not coexpression. The stained tissue microarray slides were digitized using the TissueFAXS system. HistoQuest software was used for detecting and quantifying stained regions. Two markers, the AEC master marker (ILK, pNF- $\mathrm{kB}$, or Ki-67) and the hematoxylin non-master marker, were analyzed and calculated.

\section{Cell viability and cytotoxicity assays}

To measure cell growth, cell viability was determined using a colorimetric assay (Cell Counting Kit-8; Dojindo Molecular Technologies, Kumamoto, Japan) according to the manufacturer's instructions. A microplate reader (SpectraMax 340PC; Molecular Devices Corporation, Sunnyvale, CA, USA) was used to measure the absorbance at $450 \mathrm{~nm}$, and the data were analyzed using Softmax Pro software (Molecular Devices Corporation). The relative growth rate was calculated by normalization to the control group. To evaluate cell damage, lactate dehydrogenase (LDH) activity was determined using a colorimetric assay (Cytotoxicity Detection Kit; Roche Diagnostics, Lewes, UK) according to the manufacturer's instructions. Aliquots of culture media were transferred to 96-well microplates. SpectraMax 340PC was used to measure the absorbance at $620 \mathrm{~nm}$ with a reference wavelength of $450 \mathrm{~nm}$, and the data were analyzed using Softmax Pro software.

\section{Western blotting}

Harvested cells were lysed in a buffer containing 1\% Triton X-100, $50 \mathrm{mM}$ Tris (pH 7.5), $10 \mathrm{mM}$ EDTA, 0.02\% $\mathrm{NaN}_{3}$, and a protease inhibitor cocktail (Roche Boehringer 
Mannheim Diagnostics, Mannheim, Germany). After a freeze-thaw cycle, cell lysates were centrifuged at $10,000 \times g$ at $4^{\circ} \mathrm{C}$ for $20 \mathrm{~min}$. The lysates were boiled in a sample buffer for $5 \mathrm{~min}$. Proteins were then subjected to SDS-PAGE and transferred to PVDF membranes (Millipore, Billerica, MA, USA) using a semi-dry electroblotting system. After blocking with 5\% skim milk in PBS, the membranes were incubated overnight with a 1:1,000 dilution of primary antibodies at $4^{\circ} \mathrm{C}$. The membranes were then washed with $0.05 \%$ PBS-Tween 20 and incubated with a 1:5,000 dilution of HRPconjugated secondary antibody at room temperature for $1 \mathrm{~h}$. After washing, the membranes were soaked in ECL solution (PerkinElmer Life and Analytical Sciences, Inc., Boston, MA, USA) for $1 \mathrm{~min}$ and exposed to an Xray film (BioMax; Eastman Kodak, Rochester, NY, USA). The relative signal intensity was quantified using ImageJ software (version 1.41o; W. Rasband, National Institutes of Health, Bethesda, MD, USA). The changes in the ratio of proteins compared with the normalized value of untreated cells (indicated protein $/ \beta$-actin or phosphorylated protein/total protein/ $\beta$-actin) are also determined. One set of representative data obtained from three independent experiments is shown and the data shown as the mean \pm SD values from three independent experiments (Additional file 15: Figure S14).

\section{Lentiviral-based RNAi transfection}

Protein expression was downregulated using lentiviralbased short hairpin RNA (shRNA) targeting the indicated sequences of the different genes, as summarized in Additional file 16: Table S1. Luciferase shRNA (shLuc) was used as a negative control. shRNA clones were obtained from the National RNAi Core Facility, Institute of Molecular Biology and Genomic Research Center, Academia Sinica, Taipei, Taiwan. Lentiviruses were produced by the RNAi Core Facility, National Cheng Kung University. Cells were transduced by lentiviruses with an appropriate multiplicity of infection in complete growth medium supplemented with polybrene (Sigma-Aldrich). After transduction for $24 \mathrm{~h}$ and puromycin (Calbiochem, San Diego, CA, USA) selection for 3 days, protein expression was monitored by western blotting. IQGAP1 expression was silenced using the commercial siRNA IQGAP1-HSS113014, containing the following siRNA target sequences: 5'-UUUAGCUGCAGGAAUCUGUA GGGCC-3' and 5'-GGCCCUACAGAUUCCUGCAGC UAAA-3' (Invitrogen). Transfection was performed by electroporation by using a pipette-type microporator (Microporator system; Digital Bio Technology, Suwon, Korea). After transfection, cells were incubated for $18 \mathrm{~h}$ in RPMI 1640 at $37^{\circ} \mathrm{C}$ before infection. A nonspecific scrambled siRNA (Stealth RNAi ${ }^{m}$ siRNA Negative Control Kit, 12935-100; Invitrogen) was used as the negative control.

\section{Electrophoretic mobility shift assays}

Cells were incubated in $300 \mu \mathrm{L}$ buffer A [10 mM HEPES ( $\mathrm{pH}$ 7.9), $1.5 \mathrm{mM}$ magnesium chloride, $10 \mathrm{mM}$ potassium chloride, $0.5 \mathrm{mM}$ phenylmethylsulfonyl fluoride, $0.5 \mathrm{mM}$ dithiothreitol, $2 \mu \mathrm{g} / \mathrm{mL}$ leupeptin, $10 \mu \mathrm{g} / \mathrm{mL}$ aprotinin, $50 \mathrm{mM}$ sodium fluoride, and $1 \mathrm{mM}$ sodium orthovanadate] on ice for $10 \mathrm{~min}$ and gently shaken for 10 s. The pellet containing crude nuclei was collected using centrifugation at $12,000 \times g$ for $10 \mathrm{~s}$, resuspended in $30 \mu \mathrm{l}$ buffer C [20 mM HEPES ( $\mathrm{pH} 7.9$ ), 25\% glycerol, $420 \mathrm{mM}$ sodium chloride, $1.5 \mathrm{mM}$ magnesium chloride, $0.2 \mathrm{mM}$ EDTA, $0.5 \mathrm{mM}$ phenylmethylsulfonyl fluoride, $0.5 \mathrm{mM}$ dithiothreitol, $2 \mu \mathrm{g} / \mathrm{mL}$ leupeptin, $10 \mu \mathrm{g} / \mathrm{mL}$ aprotinin, $50 \mathrm{mM}$ sodium fluoride, and $1 \mathrm{mM}$ sodium orthovanadate] by vortexing for $15 \mathrm{~s}$, followed by incubation on ice for $20 \mathrm{~min}$. After centrifuging the cells at $12,000 \times g$ for $2 \mathrm{~min}$, the supernatant containing nuclear proteins was collected, quantified (BCA Protein Assay Reagent; Pierce Biotechnology, Inc., Rockford, IL, USA), and stored in aliquots at $-70^{\circ} \mathrm{C}$. The electrophoretic mobility shift assay (EMSA) used the following oligonucleotides as probes: NF- $\mathrm{kB}$ (f): 5' ${ }^{\prime}$ CAA ATG TGG GAT TTT CCC ATG AGT; NF-kB (r): 5'-GAC TCA TGG GAA AAT CCC ACA TTT G. The forward and reverse oligonucleotides (30 pmol) were placed in $23 \mu \mathrm{L}$ of DNA polymerase buffer (Klenow 1X; Promega, Madison, WI, USA), heated at $94^{\circ} \mathrm{C}$ for $2 \mathrm{~min}$, and annealed at room temperature for $30 \mathrm{~min}$. The annealed double-stranded oligonucleotides were end-labeled using a fill-in reaction with Klenow polymerase. One unit of Klenow and $40 \mu \mathrm{Ci}$ of $\left[{ }^{32} \mathrm{P}\right] \mathrm{dCTP}$ (PerkinElmer Life and Analytical Sciences, Inc.) were added to the annealed oligonucleotides, and the mixture was incubated at $30^{\circ} \mathrm{C}$ for $15 \mathrm{~min}$. The labeled oligonucleotides were purified using G-50 columns (Sephadex; PerkinElmer Life and Analytical Sciences, Inc.). The DNA-binding reaction was performed at $4^{\circ} \mathrm{C}$ for $30 \mathrm{~min}$ in a mixture containing $3 \mu \mathrm{g}$ of nuclear extract, $10 \mathrm{mM}$ Tris- $\mathrm{HCl}$ [pH 7.5], $50 \mathrm{mM}$ sodium chloride, $0.5 \mathrm{mM}$ dithiothreitol, $0.5 \mathrm{mM}$ EDTA, $1 \mathrm{mM}$ magnesium chloride, $4 \%$ glycerol, $0.05 \mu \mathrm{g}$ poly (dI-dC)-poly (dI-dC) (PerkinElmer Life and Analytical Sciences, Inc.), and $2 \times 10^{4} \mathrm{cpm}$ ${ }^{32}$ P-labeled double-stranded oligonucleotides. Samples were analyzed on a $4 \%$ polyacrylamide gel (acrylamide/ bis-acrylamide 29:1 in 0.5 $\times$ Tris-borate-EDTA buffer) at $10 \mathrm{~V} / \mathrm{cm}$ for $2 \mathrm{~h}$. The gel was dried and analyzed using a quantitative autoradiography densitometer.

\section{Luciferase reporter assay}

To analyze NF- $\mathrm{kB}$ promoter activity by a luciferase reporter assay, transient transfection was performed using the GeneJammer transfection reagent (Stratagene, La Jolla, CA, USA). In short, cells were cotransfected with $0.2 \mu \mathrm{g}$ of an NF- $\mathrm{kB}$-promoter-driven firefly luciferase reporter and $0.01 \mu \mathrm{g}$ of a Renilla luciferase-expressing 
plasmid (pRL-TK; Promega). Twenty hours after transfection, the cells were lysed and harvested for firefly and Renilla luciferase using the Dual-Glo luciferase assay system (Promega). For each lysate, firefly luciferase activity was normalized to Renilla luciferase activity to assess transfection efficiencies.

\section{Ras pull-down assay}

Ras activation assays were performed according to the affinity precipitation protocol provided by the manufacturer (Ras Activation Assay Kit 28820; Single Oak Drive, Temecula, CA, USA). Cell lysates were incubated with Raf-1 RBD for $45 \mathrm{~min}$ at $4^{\circ} \mathrm{C}$ and centrifuged to pellet agarose beads. The agarose beads were washed, and the pellets were resuspended in $2 \times$ Laemmli sample buffer and boiled for $5 \mathrm{~min}$. The supernatant was collected, and cellular proteins were resolved by SDS-PAGE and analyzed by immunoblotting.

\section{Coimmunoprecipitation}

For coimmunoprecipitation, $100 \mu \mathrm{g}$ cell lysate from cells was incubated overnight at $4{ }^{\circ} \mathrm{C}$ with $5 \mu \mathrm{g}$ protein $\mathrm{G}$ (Amersham Biosciences, Uppsala, Sweden) and $2 \mu \mathrm{g}$ of antibodies. The expression of interacting proteins was determined by Western blotting.

\section{Transfection}

Transient transfection was performed using an MP-100 Microporator (Digital Biotechnology) according to the manufacturer's instructions for optimization and usage. The plasmid expressing EGFP-PTEN (ID NM_000314; Plasmid 13039) and its control pcDNA3-EGFP (Plasmid 13031); pWZL-Neo-Myr-Flag-ILK (ID NM 004517; Plasmid 20505) and its control pWZL-Neo-Myr-Flag-Dest (Plasmid 15300); and wild-type EGFR (Plasmid 11011), EGFR dominant-negative mutant (EGFRVIII) (Plasmid 11015) and their control vector pBABE-puro (Plasmid 1764) were purchased from Addgene (Cambridge, MA, USA). ILK dominant-negative mutant (ILK $\mathrm{A}_{\mathrm{A} 262 \mathrm{~V}}$ ) (ID NM_004517) was purchased from OriGene Technologies, Inc. (Rockville, MD, USA). Three FLAG-tagged recombinant ILK proteins, full-length $\mathrm{ILK}_{1-452}, \mathrm{~N}$ terminal truncated $\mathrm{ILK}_{171-452}$, and C-terminal truncated ILK $_{1-171}$, were constructed as described previously [18]. After transfection, the cells were cultured for $24 \mathrm{~h}$ before the experiments.

\section{PI3K activity assay}

A PIP3 Mass ELISA (K-2500 s, Echelon Biosciences, Salt Lake City, UT, USA) was performed to detect PI3K activity in cells according to the manufacturer's instructions.

\section{Wound healing assay}

For cell migration assays, the confluent monolayers of cells were wounded by scraping a pipette tip across the monolayer. The cells were washed with PBS and incubated with appropriate media. Images at $100 \times$ magnification were taken at wounding and $12 \mathrm{~h}$ later by using a microscope (IX71; Olympus). Cell migration was assessed using ImageJ software and was reported as the number of cells that migrated into the scraped region.

\section{Apoptosis assay}

Apoptosis was assessed using nuclear propidium iodide (PI; Sigma-Aldrich) staining and flow cytometry (FACSCalibur; Becton Dickinson, San Jose, CA, USA) with excitation at $488 \mathrm{~nm}$ and emission in the FL2 channel (565-610 nm). Samples were analyzed using CellQuest Pro 4.0.2 software (Becton Dickinson), and quantification was performed using WinMDI 2.8 software (The Scripps Institute, La Jolla, CA, USA). Apoptosis levels were reported as the percentages of sub- $\mathrm{G}_{1}$ phase cells.

\section{Statistical analyses}

Values were expressed as mean \pm standard deviation (SD). Significant differences between groups were assessed using one-way ANOVA followed by Dunnett's post hoc test as appropriate, Student's $t$ test, or analysis of variance. Analyses were performed using GraphPad Prism 4 software (GraphPad Software Inc., La Jolla, CA, USA). After the densities of the detected proteins were quantified using HistoQuest software, logistic regression analysis of the graded expression of ILK, phosphorylated NF-kB Ser536, and Ki-67 in 93 gastric cancer specimens tested was performed. After the AEC-based immunohistochemistry assay, no AEC staining was considered negative, $<25 \%$ staining was considered grade 1, between $25 \%$ and $50 \%$ staining was considered grade 2 , and $>50 \%$ staining was considered grade 3. Data analysis was performed using multinomial logistic regression and the pseudo Rsquared test in GraphPad Prism 4 software (GraphPad Software Inc.). The exact $P$-values are listed in the corresponding figure legends. Statistical significance was set at $P<0.05$.

\section{Supplemental materials and methods}

The additional information was also attached (Additional file 1: Supplemental materials and methods).

\section{Additional files}

Additional file 1: Supplemental materials and methods.

Additional file 2: Figure S1. Expression of ILK in gastric tumors. The representative AEC-based immunohistochemical staining of ILK and Ki-67 in 2 gastric tumor patients. Hematoxylin is used for nuclear counterstaining. 
Additional file 3: Figure S2. ILK regulates cell growth and NE-KB activation. (A) WST-8-based assay showed cell growth hi gastric cancer cell lines AGS, SNU-I, MKN45, and GES-I compared with the status at Day 0 . Western blotting (B) and immunostaining (C) showed ILK expression. $\beta$-actin was used as an internal control. The mean fluorescent intensity (MEI) per tested cell is also shown. (B) Western blotting showed ILK expression in shLuc- and shILK-transfected A549 and HI975 human lung adenocarcinoma cells, HK2 human renal proximal tubular epithelial cells, and THP 1 human acute monocytic leukemia cells. $\beta$-actin was used as an internal control. (E) Silencing ILK retarded cell growth. (F) shLuc- or shILK-transfected AGS cells were cultured for 14 days, and colony formation was manually counted. PI staining followed by flow cytometry analysis showed the cell cycle in shLuc- or shlLK-transfected AGS cells treated with vinorelbine (VNR. $1 \mu \mathrm{M})(\mathbf{G})$ and in AGS cells treated with T315 (H) for $24 \mathrm{~h}$ compared with DMSO-treated groups. The percentages of cells at the indicated phases are shown. (I) Immunostaining showing the nuclear translocation of NF-KB. (J) NF-KB activation in shLuc- and shlLK-transfected cells was determined. For cell growth, cell cycle, and luciferase activity, data are the means \pm SD from three individual experiments. tp $<0.001$ compared with Day 0 or relative control. \#P $<0.05$ and \#\#P $<0.01$ compared with shLuc.

Additional file 4: Figure S3. Expression of ILK, phosphorylated NF-KB, and Ki-67 in. gastric tumors. (A) The representative AEC-based immunohistochemical staining showed the expression of ILK, phosphorylated NF-KB at Ser536, and Ki-67 in a gastric tissue array containing 150 cases. Hematoxylin is used for nuclear counterstaining. An example of triple-positive staining is shown. (B) Ninety-three of 150 cases of gastric cancer specimens were statistically analyzed for the graded expression (Grade I, <25\%; Grade II, 25-50\%; Grade III, >50\% of observed region) of these proteins by a logistic regression analysis.

Additional file 5: Figure S4. ILK facilitates ERK1/2 signaling. (A) The Human Phospho-Kinase Array (Catalog \# ARY003B, R \& D systems) was performed to detect the phosphorylation of 43 kinases and 2 related total proteins in AGS and MKN45 cells. The mean raw density is shown as the mean data of changed kinases and the positive controls as indicated. Western blotting showed the expression of the indicated proteins in shLuc- and shILK-transfected cells (B), and PD98059-treated AGS cells (C), and $\beta$-actin was used as an internal control. (D) Cell cycle analysis showed the effects of PD98059 treatment for 48 h. (E) Western blotting showed the expression of IQGAP1, IQGAP2, and IQGAP3 in AGS, MKN45, and shLuc- or shlLK-transfected AGS cells. In shLuc- or shlQGAP3-transfected AGS cells, the expression of the indicated proteins (F), NF-kB activation (G), and cell growth $(\mathbf{H})$ were also determined. For cell cycle, luciferase activity, and proliferation assay, data are the means \pm SD from three individual experiments. NS, not significant. Regular triangle, increased expression; inverted triangle, decreased expression.

Additional file 6: Figure S5. Expression of ILK, IQGAP1, and Ras in AGS cells. The representative fluorescence-based immunohistochemical staining of ILK (green), IQGAP1 (red), and Ras (red) in AGS cells. DAPI (blue) is used for nuclear counterstaining.

Additional file 7: Figure S6. Expression of integrins in AGS and MKN45 cells. One representative histogram of immunostaining followed by flow cytometry analysis shows the expression of $\beta 1$ and $\beta 3$ integrins and the active form of $\beta 1$ integrin in AGS and MKN45 cells. $2^{\circ} \mathrm{Ab}$, secondary antibody.

Additional file 8: Figure S7. ILK facilitates ERK1/2 phosphorylation. AGS cells were treated with PD98059, LY294002, T315, or Ras inhibitor FTI-277 for the indicated times. Western blotting showed the expression of the indicated proteins. $\beta$-actin was used as an internal control.

Additional file 9: Figure S8. AKT is not required for ILK stabilization in AGS cells. Western blotting showed the expression of ILK and phosphorylated AKT at Ser473 (pAKT S) in AGS cells treated with LY294002 and AKT inhibitor 5-(2-Benzothiazolyl)-3-ethyl-2-[2-(methylphenylamino) ethenyl]-1phenyl-1H-benzimidazoli um iodide (AKTi, $2.5 \mu \mathrm{M})$. $\beta$-actin was used as an internal control. Inverted triangle, decreased expression.

Additional file 10: Figure S9. HSP90 signaling regulates ILK stabilization and ERK1/2/NF-KB signaling. Western blotting shows the expression of the indicated proteins in AGS cells treated with 17-AAG (A) and SAHA in the presence of MG132 (C). $\beta$-actin was used as an internal control. (B) Reporter assay detected NF-KB activation in AGS cells treated with SAHA (5 $\mu$ M) for $24 \mathrm{~h}$. Data are the means \pm SD from three individual experiments. ${ }^{*} P<0.05$ compared with DMSO. Regular triangle, increased expression; inverted triangle, decreased expression.

Additional file 11: Figure S10. MG132 treatment reverses ILK expression to facilitate ERK1/2/NFKB activation in MKN45 cells. Western blotting showed ILK expression and phosphorylation of MEK1/2 and ERK1/2 in MKN45 cells treated with MG132. $\beta$-actin was used as an internal control. Regular triangle, increased expression,

Additional file 12: Figure S11. Signaling of PI3K/HSP90/CHIP/ILK/ERK1/ 2/NF-KB determines cell migration. Migration activity was tested in AGS, MKN45, shlLK- or silQGAP1-transfected AGS cells (A), LY294002 (25 M), 17-AAG $(0.2 \mu \mathrm{M})$, T315 $(2.5 \mu \mathrm{M}), 9$ PD98059 $(50 \mu \mathrm{M})$, or CAPE $(25 \mu \mathrm{g} / \mathrm{ml})$ treated AGS cells (B), and shLuc- or shCHIP-transfected AGS cells treated with LY294002 (25 $\mu \mathrm{M})$ and 17-AAG $(0.2 \mu \mathrm{M})$ (C) for $12 \mathrm{~h}$. shLuc, control siRNA, or DMSO were used as the negative controls. A representative image in the observed field is shown. The numbers of migrated cells in the observed field are shown. (D) PI staining followed by flow cytometry analysis showed 5-FU- or cisplatin-induced apoptosis for 2 days in AGS or MKN45 cells pre-treated with T315 for $0.5 \mathrm{~h}$. DMSO were used as the negative controls. Data are the means \pm SD from three individual experiments. ${ }^{*} P<0.05$, ${ }^{* *} P<0.01$ and ${ }^{* *} P<0.001$ compared with relative control. $\# P<0.05$, $\# \#<0.01$, and \#\#P< 0.001 compared with relative control.

Additional file 13: Figure S12. ILK individually determines activation of AKT and ERK1/2 in response to different stimuli. Western blotting showed the phosphorylation of AKT at Ser473 (pAKT S) and ERK1/2 at Tyr202/ Thr204 (pERK1/2) in shLuc- or shlLK-transfected A549 or MKN45 cells with EGF $(10 \mathrm{ng} / \mathrm{ml})(\mathbf{A})$ and hydrogen peroxide $(\mathrm{H} 2 \mathrm{O} 2,10 \mu \mathrm{M})(\mathbf{B})$ treatment for $1 \mathrm{~h}$ or Helicobater pylori (H. pylori, $\mathrm{MOI}=10$ ) infection for $6 \mathrm{~h}$ (C). $\beta$-actin was used as an internal control. Regular triangle, increased expression; inverted triangle, decreased expression.

Additional file 14: Figure S13. PAK1 is regulated for c-Raf/ERK1/2 signaling, NF-KB activation and cell proliferation but not for ILK stabilization. AGS cells were treated with LY294002 for 24 h (A) and transfected with shLuc and shPAK1 clones \#1 and \#2 (B). Western blotting showed the expression of the indicated proteins. $\beta$-actin was used as an internal control. The activation of NF-KB (C) and cell proliferation (D) in shLuc- and shPAK1-transfected AGS cells were determined. For luciferase activity and cell proliferation, data are the means \pm SD from three individual experiments. ${ }^{* *} P<0.01$ compared with shLuc. Inverted triangle, decreased expression.

Additional file 15: Figure S14. Quantification of protein expression. For the immunoblots 10 and immunoprecipitation data in the indicated figures, the relative signal intensity was quantified using ImageJ software. The changes in the ratio of proteins compared with the normalized value of untreated cells (indicated protein/ $\beta$-actin or phosphorylated protein/ total protein/ $\beta$-actin) are also determined. The data shown as the mean \pm SD values from three independent experiments. ${ }^{*} P<0.05,{ }^{*} P<0.01$, and ${ }^{* * *} P<0.001$ compared with the relative controls. $\# P<0.05$, \#\#P<0.01, and $\# \# P<0.001$ compared with the indicated controls. ns, not significant.

Additional file 16: Table S1. Target sequences of shRNAs used in this study.

\section{Abbreviations}

ANK: Ankyrin; CHIP: HSP90-associated E3 ubiquitin ligase C-terminus of heat shock cognate 70-interacting protein; ECM: Extracellular matrix; ERK: Extracellular signal-regulated protein kinase; GSK: Glycogen synthase kinase; HSP: Heat shock protein; ILK: Integrin-linked kinase; IQGAP: IQ motif-containing GTPase-activating protein; MAPK: Mitogen-activated protein kinase; PH: Pleckstrin homology; PI3K: Phosphatidylinositol 3-kinase; PIP2: Phosphatidylinositol 4,5-bisphosphate (PIP2); PIP3: Phosphatidylinositol 3,4,5-triphosphate (PIP3); PTEN: Phosphatase and tensin homolog deleted on chromosome 10; siRNA: Short interfering RNA; shRNA: Short hairpin RNA.

\section{Competing interests}

The authors declare that they have no competing interests. 


\section{Authors' contributions}

PCT, CLC, and CFL designed experiments. PCT and CFL wrote the manuscript. CLC, YSS, WTC, HSL, and TMH edited and revised the manuscript as well as prepared major reagents. PCT and $\mathrm{CYH}$ performed experiments and analyzed the data. SHL provided statistical consulting support. All authors read and approved the final version of this manuscript.

\section{Acknowledgements}

We thank the Immunobiology Core, Research Center of Clinical Medicine, National Cheng Kung University Hospital for providing services, including training, technical support, and assistance with the experimental design and data analysis using the Flow Cytometry Core facilities. This study was supported by grant NSC 100-2320-B-006-009-MY3 from the National Science Council, Taiwan.

\section{Author details}

${ }^{1}$ Institute of Clinical Medicine, College of Medicine, National Cheng Kung University, Tainan 701, Taiwan. ${ }^{2}$ Center for Translational Medicine, Taipei Medical University, Taipei 110, Taiwan. ${ }^{3}$ Department of Surgery, College of Medicine, National Cheng Kung University, Tainan 701, Taiwan. ${ }^{4}$ Department of Biological Science and Technology, Chung Hwa University of Medical Technology, Tainan 717, Taiwan. ${ }^{5}$ Department of Microbiology and Immunology, College of Medicine, National Cheng Kung University, Tainan 701, Taiwan. ${ }^{6}$ Center of Infectious Disease and Signaling Research, College of Medicine, National Cheng Kung University, Tainan 701, Taiwan. ${ }^{7}$ Graduate Institute of Medical Sciences, College of Medicine, Taipei Medical University, Taipei 110, Taiwan. ${ }^{8}$ Department of Microbiology and Immunology, College of Medicine, Taipei Medical University, Taipei 110, Taiwan.

Received: 7 May 2014 Accepted: 19 October 2014

Published online: 15 November 2014

\section{References}

1. Hannigan GE, Leung-Hagesteijn C, Fitz-Gibbon L, Coppolino MG, Radeva G, Filmus J, Bell JC, Dedhar S: Regulation of cell adhesion and anchoragedependent growth by a new beta 1-integrin-linked protein kinase. Nature 1996, 379:91-96.

2. Wu C, Dedhar S: Integrin-linked kinase (ILK) and its interactors: a new paradigm for the coupling of extracellular matrix to actin cytoskeleton and signaling complexes. J Cell Biol 2001, 155:505-510.

3. Persad S, Dedhar S: The role of integrin-linked kinase (ILK) in cancer progression. Cancer Metastasis Rev 2003, 22:375-384

4. Delcommenne M, Tan C, Gray V, Rue L, Woodgett J, Dedhar S: Phosphoinositide-3-OH kinase-dependent regulation of glycogen synthase kinase 3 and protein kinase B/AKT by the integrin-linked kinase. Proc Natl Acad Sci U S A 1998, 95:11211-11216.

5. Cabodi S, del Pilar Camacho-Leal M, Di Stefano P, Defilippi P: Integrin signalling adaptors: not only figurants in the cancer story. Nat Rev Cancer 2010, 10:858-870.

6. McDonald PC, Fielding AB, Dedhar S: Integrin-linked kinase-essential roles in physiology and cancer biology. J Cell Sci 2008, 121:3121-3132.

7. Dobreva I, Fielding A, Foster LJ, Dedhar S: Mapping the integrin-linked kinase interactome using SILAC. J Proteome Res 2008, 7:1740-1749.

8. Morimoto AM, Tomlinson MG, Nakatani K, Bolen JB, Roth RA, Herbst R: The MMAC1 tumor suppressor phosphatase inhibits phospholipase $C$ and integrin-linked kinase activity. Oncogene 2000, 19:200-209.

9. Persad S, Attwell S, Gray V, Mawji N, Deng JT, Leung D, Yan J, Sanghera J, Walsh MP, Dedhar S: Regulation of protein kinase B/Akt-serine 473 phosphorylation by integrin-linked kinase: critical roles for kinase activity and amino acids arginine 211 and serine 343. J Biol Chem 2001, 276:27462-27469.

10. Wu X, Senechal K, Neshat MS, Whang YE, Sawyers CL: The PTEN/MMAC1 tumor suppressor phosphatase functions as a negative regulator of the phosphoinositide 3-kinase/Akt pathway. Proc Natl Acad Sci U S A 1998, 95:15587-15591.

11. Cantley LC, Neel BG: New insights into tumor suppression: PTEN suppresses tumor formation by restraining the phosphoinositide 3-kinase/AKT pathway. Proc Natl Acad Sci U S A 1999, 96:4240-4245.

12. D'Amico M, Hulit J, Amanatullah DF, Zafonte BT, Albanese C, Bouzahzah B, Fu M, Augenlicht LH, Donehower LA, Takemaru K, Moon RT, Davis R, Lisanti MP, Shtutman M, Zhurinsky J, Ben-Ze'ev A, Troussard AA, Dedhar S, Pestell
RG: The integrin-linked kinase regulates the cyclin D1 gene through glycogen synthase kinase 3 beta and CAMP-responsive element-binding protein-dependent pathways. J Biol Chem 2000, 275:32649-32657.

13. Makino K, Day CP, Wang SC, Li YM, Hung MC: Upregulation of IKKalpha/ IKKbeta by integrin-linked kinase is required for HER2/neu-induced NF-kappaB antiapoptotic pathway. Oncogene 2004, 23:3883-3887.

14. Agouni A, Sourbier C, Danilin S, Rothhut S, Lindner V, Jacqmin D, Helwig Jر J, Lang H, Massfelder T: Parathyroid hormone-related protein induces cell survival in human renal cell carcinoma through the PI3K Akt pathway: evidence for a critical role for integrin-linked kinase and nuclear factor kappa B. Carcinogenesis 2007, 28:1893-1901.

15. Medici D, Nawshad A: Type I collagen promotes epithelial-mesenchymal transition through ILK-dependent activation of NF-kappaB and LEF-1. Matrix Biol 2010, 29:161-165.

16. Hashiramoto A, Murata M, Kawazoe T, Yoshida K, Akiyama C, Shiozawa K, Shiozawa S: Heat shock protein 90 maintains the tumour-like character of rheumatoid synovial cells by stabilizing integrin-linked kinase, extracellular signal-regulated kinase and protein kinase B. Rheumatology (Oxford) 2011, 50:852-861.

17. Wani AA, Jafarnejad SM, Zhou J, Li G: Integrin-linked kinase regulates melanoma angiogenesis by activating NF-kappaB/interleukin- 6 signaling pathway. Oncogene 2011, 30:2778-2788

18. Liang CH, Chiu SY, Hsu IL, Wu YY, Tsai YT, Ke JY, Pan SH, Hsu YC, Li KC, Yang $P C$, Chen YL, Hong TM: alpha-Catulin drives metastasis by activating ILK and driving an alphavbeta3 integrin signaling axis. Cancer Res 2013, 73:428-438.

19. Zhao M, Gao Y, Wang L, Liu S, Han B, Ma L, Ling Y, Mao S, Wang X: Overexpression of integrin-linked kinase promotes lung cancer cell migration and invasion via NF-kappaB-mediated upregulation of matrix metalloproteinase-9. Int J Med Sci 2013, 10:995-1002.

20. Liang F, Zhang S, Wang B, Qiu J, Wang Y: Overexpression of integrin-linked kinase (ILK) promotes glioma cell invasion and migration and downregulates E-cadherin via the NF-kappaB pathway. J Mol Histol 2013, 45:141-151.

21. Zhang Y, Chen K, Tu Y, Wu C: Distinct roles of two structurally closely related focal adhesion proteins, alpha-parvins and beta-parvins, in regulation of cell morphology and survival. J Biol Chem 2004, 279:41695-41705.

22. Huang $Y, L i$ J, Zhang $Y$, Wu C: The roles of integrin-linked kinase in the regulation of myogenic differentiation. J Cell Biol 2000, 150:861-872.

23. Noguchi S, Yasui Y, Iwasaki J, Kumazaki M, Yamada N, Naito S, Akao Y: Replacement treatment with microRNA-143 and -145 induces synergistic inhibition of the growth of human bladder cancer cells by regulating PI3K/ Akt and MAPK signaling pathways. Cancer Lett 2013, 328:353-361.

24. Dedhar S: Cell-substrate interactions and signaling through ILK. Curr Opin Cell Biol 2000, 12:250-256.

25. Aoyagi Y, Fujita N, Tsuruo T: Stabilization of integrin-linked kinase by binding to Hsp90. Biochem Biophys Res Commun 2005, 331:1061-1068.

26. Radovanac K, Morgner J, Schulz JN, Blumbach K, Patterson C, Geiger T, Mann M, Krieg T, Eckes B, Fassler R, Wickstrom SA: Stabilization of integrinlinked kinase by the Hsp90-CHIP axis impacts cellular force generation, migration and the fibrotic response. EMBO J 2013, 32:1409-1424.

27. Malumbres M, Barbacid M: RAS oncogenes: the first 30 years. Nat Rev Cancer 2003, 3:459-465.

28. Ito R, Oue N, Zhu X, Yoshida K, Nakayama H, Yokozaki H, Yasui W: Expression of integrin-linked kinase is closely correlated with invasion and metastasis of gastric carcinoma. Virchows Arch 2003, 442:118-123.

29. Graff JR, Deddens JA, Konicek BW, Colligan BM, Hurst BM, Carter HW, Carter $\mathrm{J}$ : Integrin-linked kinase expression increases with prostate tumor grade. Clin Cancer Res 2001, 7:1987-1991.

30. Takanami I: Increased expression of integrin-linked kinase is associated with shorter survival in non-small cell lung cancer. BMC Cancer 2005, 5:1.

31. Aviel-Ronen S, Blackhall FH, Shepherd FA, Tsao MS: K-ras mutations in non-small-cell lung carcinoma: a review. Clin Lung Cancer 2006, 8:30-38.

32. Moul JW, Friedrichs PA, Lance RS, Theune SM, Chang EH: Infrequent RAS oncogene mutations in human prostate cancer. Prostate 1992, 20:327-338.

33. Hiyama T, Haruma K, Kitadai Y, Masuda H, Miyamoto M, Tanaka S, Yoshihara M, Shimamoto F, Chayama K: K-ras mutation in helicobacter pylori-associated chronic gastritis in patients with and without gastric cancer. Int J Cancer 2002, 97:562-566. 
34. Zhao G, Guo LL, Xu JY, Yang H, Huang MX, Xiao G: Integrin-linked kinase in gastric cancer cell attachment, invasion and tumor growth. World J Gastroenterol 2011, 17:3487-3496.

35. Soutto $M$, Belkhiri $A$, Piazuelo MB, Schneider $B G$, Peng $D$, Jiang $A$, Washington MK, Kokoye Y, Crowe SE, Zaika A, Crowe SE, Zaika A, Correa P, Peek RM Jr, El-Rifai W: Loss of TFF1 is associated with activation of NF-kappaB-mediated inflammation and gastric neoplasia in mice and humans. J Clin Invest 2011, 121:1753-1767.

36. Lee SL, Hsu EC, Chou CC, Chuang HC, Bai LY, Kulp SK, Chen CS: Identification and characterization of a novel integrin-linked kinase inhibitor. J Med Chem 2011, 54:6364-6374.

37. Yoon YK, Kim HP, Han SW, Hur HS, Oh Do Y, Im SA, Bang YJ, Kim TY: Combination of EGFR and MEK1/2 inhibitor shows synergistic effects by suppressing EGFR/HER3-dependent AKT activation in human gastric cancer cells. Mol Cancer Ther 2009, 8:2526-2536.

38. Ravi R, Bedi A: NF-kappaB in cancer-a friend turned foe. Drug Resist Updat 2004, 7:53-67.

39. Roy M, Li Z, Sacks DB: IQGAP1 is a scaffold for mitogen-activated protein kinase signaling. Mol Cell Biol 2005, 25:7940-7952.

40. Jameson KL, Mazur PK, Zehnder AM, Zhang J, Zarnegar B, Sage J, Khavari PA: IQGAP1 scaffold-kinase interaction blockade selectively targets RAS-MAP kinase-driven tumors. Nat Med 2013, 19:626-630.

41. Knoll R, Postel R, Wang J, Kratzner R, Hennecke G, Vacaru AM, Vakeel P, Schubert C, Murthy K, Rana BK, Kube D, Knöll G, Schäfer K, Hayashi T, Holm T, Kimura A, Schork N, Toliat MR, Nürnberg P, Schultheiss HP, Schaper W, Schaper J, Bos E, Den Hertog J, van Eeden FJ, Peters PJ, Hasenfuss G, Chien $K R$, Bakkers J: Laminin-alpha4 and integrin-linked kinase mutations cause human cardiomyopathy via simultaneous defects in cardiomyocytes and endothelial cells. Circulation 2007, 116:515-525.

42. Souma Y, Nishida T, Serada S, Iwahori K, Takahashi T, Fujimoto M, Ripley B, Nakajima K, Miyazaki Y, Mori M, Doki Y, Sawa Y, Naka T: Antiproliferative effect of SOCS-1 through the suppression of STAT3 and p38 MAPK activation in gastric cancer cells. Int J Cancer 2012, 131:1287-1296.

43. Tseng PC, Huang WC, Chen CL, Sheu BS, Shan YS, Tsai CC, Wang CY, Chen SO, Hsieh CY, Lin CF: Regulation of SHP2 by PTEN/AKT/GSK-3beta signaling facilitates IFN-gamma resistance in hyperproliferating gastric cancer. Immunobiology 2012, 217:926-934.

44. Emanuele MJ, Elia AE, Xu Q, Thoma CR, Izhar L, Leng Y, Guo A, Chen YN, Rush J, Hsu PW, Yen HC, Elledge SJ: Global identification of modular cullin-RING ligase substrates. Cell 2011, 147:459-474.

45. Murata S, Minami Y, Minami M, Chiba T, Tanaka K: CHIP is a chaperonedependent E3 ligase that ubiquitylates unfolded protein. EMBO Rep 2001, 2:1133-1138.

46. Alberts SR, Cervantes A, van de Velde CJ: Gastric cancer: epidemiology, pathology and treatment. Ann Oncol 2003, 14(Suppl 2):ii31-ii36.

47. Normanno N, De Luca A, Bianco C, Strizzi L, Mancino M, Maiello MR, Carotenuto A, De Feo G, Caponigro F, Salomon DS: Epidermal growth factor receptor (EGFR) signaling in cancer. Gene 2006, 366:2-16.

48. Huang PH, Xu AM, White FM: Oncogenic EGFR signaling networks in glioma. Sci Signal 2009, 2:re6.

49. Meyer-ter-Vehn T, Covacci A, Kist M, Pahl HL: Helicobacter pylori activates mitogen-activated protein kinase cascades and induces expression of the proto-oncogenes c-fos and c-jun. J Biol Chem 2000, 275:16064-16072.

50. Nakayama M, Hisatsune J, Yamasaki E, Isomoto H, Kurazono H, Hatakeyama M, Azuma T, Yamaoka Y, Yahiro K, Moss J, Hirayama T: Helicobacter pylori VacA-induced inhibition of GSK3 through the PI3K/Akt signaling pathway. J Biol Chem 2009, 284:1612-1619.

51. Ramos JW: The regulation of extracellular signal-regulated kinase (ERK) in mammalian cells. Int J Biochem Cell Biol 2008, 40:2707-2719.

52. Tang CK, Gong XQ, Moscatello DK, Wong AJ, Lippman ME: Epidermal growth factor receptor vlll enhances tumorigenicity in human breast cancer. Cancer Res 2000, 60:3081-3087.

53. White CD, Erdemir HH, Sacks DB: IQGAP1 and its binding proteins control diverse biological functions. Cell Signal 2012, 24:826-834.

54. Brill S, Li S, Lyman CW, Church DM, Wasmuth JJ, Weissbach L, Bernards A, Snijders AJ: The Ras GTPase-activating-protein-related human protein IQGAP2 harbors a potential actin binding domain and interacts with calmodulin and Rho family GTPases. Mol Cell Biol 1996, 16:4869-4878.

55. Hart MJ, Callow MG, Souza B, Polakis P: IQGAP1, a calmodulin-binding protein with a rasGAP-related domain, is a potential effector for cdc42Hs. EMBO J 1996, 15:2997-3005.
56. Wickstrom SA, Lange A, Hess MW, Polleux J, Spatz JP, Kruger M, Pfaller K, Lambacher A, Bloch W, Mann M, Huber LA, Fässler R: Integrin-linked kinase controls microtubule dynamics required for plasma membrane targeting of caveolae. Dev Cell 2010, 19:574-588.

57. Walch A, Seidl S, Hermannstadter C, Rauser S, Deplazes J, Langer R, von Weyhern CH, Sarbia M, Busch R, Feith M, Feith M, Gillen S, Höfler H, Luber B: Combined analysis of Rac1, IQGAP1, Tiam1 and E-cadherin expression in gastric cancer. Mod Pathol 2008, 21:544-552.

58. Takatsuki H, Komatsu S, Sano R, Takada Y, Tsuji T: Adhesion of gastric carcinoma cells to peritoneum mediated by alpha3beta1 integrin (VLA-3). Cancer Res 2004, 64:6065-6070.

59. Ke JJ, Shao QS, Ling ZQ: Expression of E-selectin, integrin beta1 and immunoglobulin superfamily member in human gastric carcinoma cells and its clinicopathologic significance. World J Gastroenterol 2006, 12:3609-3611.

60. King CC, Gardiner EM, Zenke FT, Bohl BP, Newton AC, Hemmings BA, Bokoch GM: p21-activated kinase (PAK1) is phosphorylated and activated by 3-phosphoinositide-dependent kinase-1 (PDK1). J Biol Chem 2000, 275:41201-41209.

61. Acconcia F, Barnes CJ, Singh RR, Talukder AH, Kumar R: Phosphorylationdependent regulation of nuclear localization and functions of integrinlinked kinase. Proc Natl Acad Sci U S A 2007, 104:6782-6787.

62. Fujita N, Sato S, Ishida A, Tsuruo T: Involvement of Hsp90 in signaling and stability of 3-phosphoinositide-dependent kinase-1. J Biol Chem 2002, 277:10346-10353.

63. Sato S, Fujita N, Tsuruo T: Modulation of Akt kinase activity by binding to Hsp90. Proc Natl Acad Sci U S A 2000, 97:10832-10837.

64. Schulte TW, Blagosklonny MV, Ingui C, Neckers L: Disruption of the Raf-1-Hsp90 molecular complex results in destabilization of Raf-1 and loss of Raf-1-Ras association. J Biol Chem 1995, 270:24585-24588.

65. Zuehlke A, Johnson JL: Hsp90 and co-chaperones twist the functions of diverse client proteins. Biopolymers 2010, 93:211-217.

66. Dan L, Jian D, Na L, Xiaozhong W: Crosstalk between EGFR and integrin affects invasion and proliferation of gastric cancer cell line, SGC7901. Onco Targets Ther 2012, 5:271-277.

67. Erez N, Truitt M, Olson P, Arron ST, Hanahan D: Cancer-Associated Fibroblasts Are Activated in Incipient Neoplasia to Orchestrate Tumor-Promoting Inflammation in an NF-kappaB-Dependent Manner. Cancer Cell 2010, 17:135-147.

doi:10.1186/s12964-014-0069-3

Cite this article as: Tseng et al:: An increase in integrin-linked kinase non-canonically confers NF-KB-mediated growth advantages to gastric cancer cells by activating ERK1/2. Cell Communication and Signaling 2014 12:69.

\section{Submit your next manuscript to BioMed Central and take full advantage of:}

- Convenient online submission

- Thorough peer review

- No space constraints or color figure charges

- Immediate publication on acceptance

- Inclusion in PubMed, CAS, Scopus and Google Scholar

- Research which is freely available for redistribution 